\title{
HISTORICIDAD TEXTUAL Y TRADICIONES \\ CULTURALES, CON ESPECIAL REFERENCIA \\ A LAS DISPOSICIONES LEGISLATIVAS EN \\ MÉXICO
}

\author{
María Eugenia Vázquez Laslop \\ El Colegio de México
}

INTRODUCCIÓN

G 1 historiador suele acudir a fuentes textuales, entre otras

Euentes documentales, para configurar un corpus de datos históricos, según sus objetivos y métodos de investigación. Los textos son ya el producto escrito de los discursos de géneros diversos, que se desarrollan en ámbitos culturales determinados y, aunque en mayor o menor medida se tiene consciencia de que tales fuentes textuales tienen su propia historia, el estudio histórico de las propiedades y formas discursivas y textuales como tales ha recaído, sobre todo, en disciplinas como la filología, la literatura, la retórica, la diplomática, la ecdótica, la paleografía y la lingüística.

El presente artículo es una reflexión acerca de la historicidad intrínseca de los textos; mejor dicho, de las tradiciones textuales y su relación con la historicidad de otras tradiciones culturales, desde la visión de la lingüística del texto, en su versión de la

Fecha de recepción: 9 de febrero de 2018

Fecha de aceptación: 8 de agosto de 2018 
teoría de las tradiciones discursivas desarrollada por los discípulos del lingüista Eugenio Coseriu.

Se destaca que los ritmos históricos de unas y otras tradiciones culturales pueden ser asincrónicos y que los moldes lingüísticos suelen ser mucho más conservadores que los de otras tradiciones culturales. Tomo como ejemplo las tradiciones textuales de las disposiciones legislativas en México (desde la Nueva España hasta las primeras décadas del siglo xxi) y su relación con las tradiciones jurídicas que las han generado.

El ejemplo es producto de una investigación lingüística acerca de los diversos moldes textuales en los que se han acomodado las leyes mexicanas desde que México es independiente ${ }^{1}$ y que explora el paso de los cánones retóricos y argumentativos de las disposiciones jurídicas indianas ${ }^{2}$ al modelo de las leyes expresadas en artículos, organizados en capítulos y títulos por materia, es decir, al propio de la era de la codificación. ${ }^{3}$ El estudio de los cambios o permanencias en los moldes textuales de una y otra tradición llevan, necesariamente, a rozar las fronteras entre la lingüística, la historia del derecho y la teoría de la historia. No obstante, las reflexiones que aquí desarrollo no dejan de hacerse desde la trinchera de la observación lingüística.

El artículo se organiza de la siguiente manera. En el $\mathbb{} 2$ expongo brevemente algunos conceptos centrales de la teoría lingüística de las tradiciones discursivas, que servirán de guía para las reflexiones del resto del artículo. Dedico el $\$ 3$ a la ejemplificación de la convivencia y las asincronías de tres tradiciones jurídicas y las tradiciones textuales de la expedición de disposiciones jurídicas en la Nueva España y México, a partir

1 VÁzquez Laslop, “Tradiciones jurídicas” y "Tradiciones e innovaciones”.

2 García Gallo, "La ley como fuente del derecho" y Tau Anzoátegui, "Acerca de la elaboración".

3 González, El derecho civil en México 1821-1871. Véase Tomás y Valiente, Manual de historia del derecho español, p. 465 y Guzmán BRITO, “'Codex”," p. 139. 
de los moldes textuales de la diplomática medieval europea. ${ }^{4}$ En la última sección-el $\$ 4$ - reflexiono brevemente acerca de cómo interpretar históricamente las tradiciones jurídicas y su relación con las textuales, en tanto tradiciones culturales, según la perspectiva hermenéutica que permite combinar elementos de la lingüística de Eugenio Coseriu con la historia conceptual de Reinhart Koselleck.

\section{SABERES LINGÜÍSTICOS, LA DOBLE HISTORICIDAD \\ DEL DISCURSO Y LAS TRADICIONES DISCURSIVAS}

Como otras disciplinas humanísticas, la lingüística contemporánea incluye entre sus áreas de estudio los aspectos históricos del fenómeno de su especialidad. Destaca sobre todo el estudio diacrónico de los cambios lingüísticos, particularmente de los fenómenos gramaticales y léxicos de las lenguas. Sin embargo, no sólo las lenguas o idiomas -como el español, el náhuatl o el japonés-son fenómenos históricos; lo es también la propia actividad lingüística en algunos de los aspectos a los que aquí me refiero.

En sentido estricto, tal y como lo explicó Eugenio Coseriu, ${ }^{5}$ al desarrollar en su teoría lingüística algunas ideas fundamentales

${ }^{4}$ Un tema que se ha tratado con más detalle en los estudios lingüísticos de Vázquez Laslop, “Tradiciones jurídicas” y "Tradiciones e innovaciones”.

${ }^{5}$ Coseriu, Sincronía, diacronía e historia, p. 45. Eugenio Coseriu (1921-2002) fue uno de los romanistas y teóricos de la lingüística más connotados del siglo xx. Aunque sus desarrollos teóricos del estructuralismo lingüístico a partir de su visión crítica del proyecto de Ferdinand de Sassure (1857-1913) abarcaron las diversas dimensiones de la lengua, su pensamiento fue mucho más allá de estos límites. Coseriu construyó un edificio conceptual y metodológico al que entendía como una "lingüística integral" cuyo punto de partida habría de ser el habla (en actividad), a diferencia de la lingüística saussureana, que privilegiaba el estudio de las estructuras de la lengua (el sistema como producto). Esta visión integral de la disciplina dio paso, entre otras cosas, al estudio de la variación lingüística en todos sus ámbitos a la luz de la lingüística coseriana, el cual ha resultado altamente fructífero en la lingüística contemporánea. Una de sus aportaciones principales es precisamente la distinción de los tres niveles 
de Wilhelm von Humboldt (1767-1835), el lenguaje existe sólo como actividad, es decir, como hablar. Las lenguas son, en realidad, productos históricos de esa actividad que la lingüística actual estudia en diversos niveles analíticos. El hablar, para Coseriu, "es una actividad humana universal que se realiza individualmente, pero siempre según técnicas históricamente determinadas ('lenguas')", ${ }^{6}$ caracterización a partir de la cual distingue tres niveles o grados del saber hablar: ${ }^{7}$ uno universal, al que denomina saber elocucional, como propiedad de la naturaleza humana; ${ }^{8}$ uno histórico, al que llama saber idiomático, es decir, un saber hablar según la tradición de una comunidad ${ }^{9}$ y que corresponde a dominar una lengua, y uno particular, el saber expresivo, en cuanto acto individual en una situación determinada.

de lo lingüístico: el universal, el histórico y el individual, uno de los fundamentos de la teoría de las tradiciones discursivas, desarrollada (por no decir continuada) por la Escuela de Tubinga y por otros de sus discípulos. Dicha teoría ha estado en boga desde la década de 1980 hasta el siglo xxi y ha tenido una amplia recepción, particularmente en la lingüística histórica del español. Respecto de la lingüística del texto de Coseriu, Lingüística del texto. Introducción a la hermenéutica del sentido, ésta no ha de confundirse con las teorías que proliferaron en la década de 1970 para el estudio de los textos. La lingüística del texto coseriana forma parte de su lingüística integral y es más cercana a disciplinas como la pragmática y la estilística. En parte, la hermenéutica del sentido se obtiene de los vínculos entre el texto y sus entornos comunicativos y se estudia en los tres niveles de lo lingüístico (el universal, el histórico y el individual), con lo cual supera también a las otras teorías de la lingüística del texto de la década de 1970. Véase KabateK, "Eugenio Coseriu (1921-2002)” y Loureda Lamas y Meisterfeld, "Eugenio Coseriu y su legado científico".

${ }^{6}$ Coseriu, Lecciones de lingüistica general, p. 269.

7 Coseriu, Lecciones de lingüística general, pp. 269-274.

${ }^{8}$ Según Coseriu, dos propiedades de la universalidad del lenguaje lo distinguen: su capacidad para referirse a la realidad extralingǘstica y la facultad de hablar que todos los seres humanos poseemos, sin una determinación histórica. Coseriu, Lingüistica del texto, pp. 130 y ss.

${ }^{9}$ Coseriu, Sincronía, p. 45. Cada lengua posee gramáticas y léxicos diversos. Coseriu, Lingüistica del texto, p. 132. 
El nivel particular corresponde al discurso en su naturaleza dinámica (según el concepto humboldtiano) cuyo producto es el texto. El texto puede ser desde un enunciado muy breve, sin estructura oracional-como por ejemplo, ;Aguas!, ${ }^{10}$ o un dicho o refrán, como Zapatero a tus zapatos- ${ }^{11}$ hasta un libro entero o más -como una enciclopedia de más de veinte volúmenes. Algunos textos, de acuerdo con Coseriu, están incorporados a una tradición lingüística determinada, ${ }^{12}$ es decir, sólo son propios de una comunidad lingüística que habla una lengua histórica. Se trata de fórmulas, por ejemplo, como las del saludo al comenzar el día: en español Buenos días, en plural, frente al francés Bon jour, en singular, pero muy diferente al alemán Guten Morgen, que puede traducirse al inglés como Good morning ("buena mañana"), con la diferencia de que en alemán la declinación gramatical (el caso acusativo) implica (o evoca) que Guten Morgen es un complemento sintáctico de un verbo no dicho, cuyo significado correspondería a algo como "desear": el sentido completo evocado sería, más o menos, "(te deseo) una buena mañana". En todos estos textos identificamos saludos que, como se comprueba, se dicen y se configuran según las reglas gramaticales y prosódicas de lenguas históricas particulares: el español, el francés, el alemán y el inglés, respectivamente.

Este saber expresivo, no obstante, no siempre depende del todo del saber idiomático o del dominio de una lengua en particular y, por lo tanto, no está incorporado a una tradición lingüístico-idiomática determinada, sino a tradiciones culturales de diversa índole. En efecto, algunos textos están configurados según determinadas modalidades históricas que responden a

10 “(Coloq) Expresión de alerta ante algún peligro: ‘ $¡$ Aguas! Ahí viene la policía” " (Diccionario del Español de México, en línea <dem.colmex.mx>, consultado el 4 de mayo de 2017).

${ }_{11}$ Para significar que sólo hemos de dedicarnos a aquello que nos toca o en lo que somos expertos.

12 Coseriu, Lingüistica del texto, p. 138. 
otro tipo de fenómenos culturales. Piénsese, por ejemplo, en la estructura textual de un soneto, de un romance o de un contrato de compra-venta. Tales estructuras provienen de tradiciones culturales no restringidas a una lengua en particular. Por ello, Coseriu los llama textos supraidiomáticos, ${ }^{13}$ cuyos moldes, de acuerdo con Brigitte Schlieben-Lange, están anclados en instituciones de grupos determinados, tales como un gremio de comerciantes, una escuela de arte poética, instituciones jurídicas, religiosas, científicas, etc., a las que llama comunidades textuales. ${ }^{14}$

De tal manera que Peter Koch, siguiendo la línea de Coseriu y de Schlieben-Lange, propone incorporar en el nivel histórico de la actividad lingüística tales tradiciones textuales o discursivas. ${ }^{15}$ La configuración tradicional de los textos proviene de técnicas lingüísticas transmitidas históricamente, que son independientes de las técnicas lingüísticas de carácter idiomático. Por ello, la teoría de las tradiciones discursivas, continuadora de la teoría lingüística de Coseriu, distingue dos dominios de la historicidad lingüística: por un lado, la historicidad primaria, que corresponde a la de las lenguas históricas particulares y, por otro, la historicidad secundaria, la de la tradición de los textos. ${ }^{16}$

Un género discursivo es una tradición discursiva, pero no todas las tradiciones discursivas son géneros discursivos. De hecho, un texto particular -o, incluso, un género discursivo- puede ser el resultado de una combinación de diversas tradiciones discursivas que se han venido heredando históricamente. Tradición implica repetición, en el caso de los textos, de fórmulas expresivas que, en ocasiones, pueden llegar a evocar todo el tipo textual, como en el caso de Érase una vez... para

\footnotetext{
13 Coseriu, Lingüistica del texto, pp. 138 y s.

14 Schlieben-Lange, Traditionen des Sprechens, p. 139.

$15 \mathrm{KocH}$, "Diskurstraditionen”, p. 45.

16 Kabatex, Die Bolognesische Renaissance, pp. 31-36. Véase también del mismo autor "Tradiciones discursivas", pp. 333-336.
} 
la convención del comienzo de un cuento o, para el final de los cuentos infantiles, y colorín colorado..., que evoca para el niño la fórmula completa -y colorín colorado, este cuento se ba acabado- o que también podría aparecer en una narración cualquiera entre adultos para indicar que ya no hay nada más que contar. Una estrategia discursiva de esta clase conlleva el conocimiento mutuo entre los interlocutores de esa técnica o tradición discursiva. Por ello, la definición de tradición discursiva de Wulf Oesterreicher incluye las convenciones de emisión y recepción comunicativas: "moldes normativos convencionalizados que guían la transmisión de un sentido mediante elementos lingüísticos tanto en su producción como en su recepción discursiva". ${ }^{17}$

Una definición más detallada es la de Johannes Kabatek, que incluye los conceptos de tradición, evocación, saber expresivo, comunicación, actividad lingüística, significación y forma textual, a los que ya me he referido:

Entendemos por Tradición discursiva [...] la repetición de un texto o de una forma textual o de una manera particular de escribir o de hablar que adquiere valor de signo propio (por lo tanto, es significable). Se puede formar en relación con cualquier finalidad de expresión o con cualquier elemento de contenido cuya repetición establece un lazo entre actualización y tradición, es decir, cualquier relación que se puede establecer semióticamente entre dos elementos de tradición (actos de enunciación o elementos referenciales) que evocan una determinada forma textual o determinados elementos lingüísticos empleados. ${ }^{18}$

17 "Diskurstraditionen oder diskurstraditionelle Kennzeichen sollen hier vorläufig bestimmt werden als normative, die Diskursproduktion und Diskursrezeption steuernde, konventionalisierte Muster der sprachlichen Sinnvermittlung” (Wulf Oesterreicher, "Zur Fundierung von Diskurstraditionen”, p. 20; la traducción al español es de KaвATEK, "Las tradiciones discursivas entre conservación e innovación”, p. 338).

18 Kaвatek, "Tradiciones discursivas y cambio lingüístico", p. 159. 
De todas formas, en el proceso histórico de las formas textuales no todo es repetición. Dado que la actualización de cada forma textual en un producto discursivo responde a necesidades comunicativas de los interlocutores en la situación enunciativa, los elementos repetidos se combinan con innovaciones expresivas que generan las nuevas comunidades textuales. Piénsese, por ejemplo, en las innovaciones expresivas adaptadas a los moldes epistolares en los mensajes de correos electrónicos o la evocación de la conversación oral e informal en las redes sociales digitales de los siglos xx y xxi que, por cierto, no sólo introducen innovaciones en las estructuras textuales, sino también en las tradiciones idiomáticas y en los sistemas de escritura alfabética, al combinarse éstos con otros recursos icónicos, como los llamados emoticones, que representan la expresividad gestual emotiva de rostros y manos.

Así que un texto cualquiera es una combinación de elementos expresivos tradicionales y de otros innovadores que, en principio, pueden ser tan solo variaciones casuales, según los entornos y los elementos particulares de una situación comunicativa determinada. Pero si alguna(s) de esas variaciones discursivas se repite(n) en otros textos de otros participantes en otras situaciones, porque cubren necesidades comunes de una comunidad textual de determinados ámbitos culturales (que, a su vez, pueden estar experimentando sus propias transformaciones) y dichas repeticiones se difunden, entonces pueden generarse nuevas convenciones que terminan incorporándose a la tradición textual y dan lugar a pequeños o grandes cambios dentro de ella.

Ilustraré este principio de la teoría de las tradiciones discursivas con generalidades del desarrollo histórico de la textualidad de las leyes mexicanas y su relación con las tradiciones jurídicas con las que están vinculadas. Se verá que el desarrollo de tales tradiciones textuales y jurídicas sigue sus propios ritmos y se comprobará que las tradiciones textuales son más conservadoras que las tradiciones jurídicas. 
MOLDES TEXTUALES EN LAS DISPOSICIONES JURÍDICAS

NOVOHISPANAS Y MEXICANAS

La diversidad textual producida por las tradiciones y prácticas jurídicas a lo largo de la historia es inmensa. Sabemos, no obstante, que esta diversidad en el mundo occidental no es tan caótica si tomamos en cuenta que los documentos jurídicos públicos y privados han seguido en mayor o menor medida los moldes grecolatinos de la retórica y de la práctica escrita, en buena parte, de corte epistolar. Por un lado, la propia reflexión jurídica occidental está plasmada en textos escritos, ya sea para ejercer la propia actividad de los juristas, para guiar el trabajo de los profesionales del derecho, para comprender la complejidad de la relación entre la jurisprudencia y la sociedad, ya sea para organizar grandes acervos de disposiciones jurídicas. Por otro lado, los actos jurídicos implican compromisos de individuos que, sucesivamente, pueden quedar sentados por escrito, a veces, con intermediarios (autoridades públicas, testigos, escribanos, notarios, etc.). En otras palabras, las rutas que ha tomado el derecho occidental privilegian, sobre todo, la necesidad de dejar en textos escritos dichos actos, con lo cual tienen lugar los efectos jurídicos correspondientes. Tal vez por todo ello Jaime del Arenal -siguiendo a su maestro Álvaro D'Ors- ha insistido en que la historia del derecho es, entre otras cosas, una historia de textos y de lenguajes. ${ }^{19}$

Dentro de este andamiaje jurídico textual se desarrolla el del derecho indiano, que organizará los actos jurídicos del mundo novohispano y que dará paso, entre otras cosas, al del derecho del México independiente. En lo que sigue propongo una gran caracterización de las tradiciones textuales de los ordenamientos jurídicos de la Nueva España y de las disposiciones legislativas

19 Arenal Fenochio, Historia minima del derecho en Occidente, pp. 17 y passim. 
del México independiente, en relación con las tradiciones jurídicas con las que se vinculan, sólo con el objeto de observar si las permanencias y los cambios o innovaciones en una y otra tradiciones culturales (las textuales y las jurídicas) siguen un mismo ritmo. Esta caracterización general cuenta ya con una base empírica en las investigaciones de María Eugenia Vázquez Laslop, ${ }^{20}$ acerca de la estructura textual de un amplio corpus de disposiciones legislativas, la mayor parte tomadas de la colección de Manuel Dublán y José María Lozano, ${ }^{21}$ así como del acervo digital de la Cámara de Diputados, ${ }^{22}$ que contiene las leyes vigentes al año de 2013 en México, decretadas entre las décadas de 1910 y 2010. En general, se observa en dicha investigación que el cambio textual de leyes que otorgaban un estatus privilegiado a la exposición de motivos que sustentaba los actos directivos de la autoridad -el propio de las leyes indianas-hacia las leyes codificadas que, en principio, habrían de desprenderse textualmente de argumentaciones retóricas de ese tipo, fue atropellado y gradual. Por ejemplo, bajo los regímenes republicanos federales o centrales del siglo xix, Vázquez Laslop ${ }^{23}$ comprobó que en más de $30 \%$ de las disposiciones legislativas se seguían vinculando discursiva o sintácticamente los predicados directivos centrales con el contexto previo de tipo argumentativo, es decir, que éste seguía formando parte del mismo documento que el de la propia ley. De hecho, durante los regímenes en los que la labor del Congreso se veía disminuida, las disposiciones legislativas con argumentación aumentaban a más de 40 por ciento.

Todo indica que el estatus de la argumentación en las disposiciones legislativas mexicanas durante el siglo XIX forma parte

\footnotetext{
20 "Tradiciones jurídicas", "Tradiciones e innovaciones".

${ }^{21}$ Dublán y Lozano (1876-1904), Legislación mexicana.

$22 \mathrm{Al}$ que se tuvo acceso en internet en el sitio <http://www.diputados.gob. $\mathrm{mx} /$ LeyesBiblio/index.htm> durante 2013, pero que todavía estaba vigente el 6 de junio de 2018.

23 "Cohesión sintáctica y argumentación en las leyes mexicanas del siglo xix."
} 
de las tradiciones discursivas provenientes, por lo menos, de la Edad Media. Por ello tomo como punto de partida el molde textual de los diplomas reales de la Edad Media (alrededor del siglo XI), cercano a los propios del ars dictaminis, i. e., del arte o la técnica de escribir cartas en prosa ampliamente desarrollada y difundida en Europa desde la Alta Edad Media, y heredera de la tradición de la transmisión oral de los mensajes. ${ }^{24}$ Estas modalidades textuales sirvieron para formular también documentos jurídicos públicos y privados. Desde la ciencia diplomática, Alberto Tamayo define el documento en dos sentidos: uno amplio, como "todo testimonio de un acontecimiento social de carácter jurídico o no jurídico escrito en materiales blandos”, 25 $\mathrm{y}$ uno restringido, como "el escrito en que se materializa y recoge un acto o negocio por el cual se crea una situación jurídica nueva, o se modifica o extingue una ya existente". ${ }^{26}$ Para la exposición del ejemplo de las grandes tradiciones textuales a continuación, me limitaré a los documentos de derecho público en el sentido de la definición restringida de Tamayo.

\section{De los diplomas reales medievales a}

las disposiciones jurídicas del derecho indiano

Como se sabe, desde la Alta Edad Media los documentos diplomáticos reales europeos se organizaban según determinados moldes textuales que, como señala Peter Koch, ${ }^{27}$ eran un conjunto de tradiciones discursivas. Protocolos de esta clase se presentaban y difundían en manuales empleados por los actores involucrados en la producción, registro, expedición, difusión, etc., de los documentos reales, desde luego, con todos los fundamentos de la retórica clásica, pero también con innovaciones

${ }^{24}$ Murphy, Rhetoric in the Middle Ages, pp. 194-268.

25 Tamayo, Archivistica, diplomática y sigilografía, p. 55.

26 TамаYo, Archivística, diplomática y sigilografía.

$27 \mathrm{KocH}$, “Urkunde, Brief und öffentliche Rede", pp. 13-44. 
propias de los glosadores, exégetas y doctores de las ya existentes universidades europeas. ${ }^{28}$

Las partes de este esquema textual general se observan en el ejemplo que nos ofrece Peter Koch, ${ }^{29}$ correspondiente a un diploma real datado en 1068, de Felipe I, rey de Francia (cuadro 1). Hay que destacar que este documento se escribe todavía en latín, pero a medida que el uso de las lenguas vernáculas europeas va ganando terreno en las esferas de poder, jurídicas y administrativas, el molde textual empleado en los documentos escritos, de todas formas, se mantiene con algunas variantes.

\section{Cuadro 1}

DIPLOMA REAL DE FELIPE I DE FRANCIA, DEL AÑO 1068

\begin{tabular}{ll}
\hline Partes & Texto \\
\hline Invocatio & In nomine sancte et individuae Trinitatis \\
Intitulatio & Phillipus, Dei gratia Francorum rex \\
Inscriptio & presentibus et futuris \\
Salutatio & in perpetuum. \\
Arenga/ & Quoniam universis in orbe regibus, quibus omnipotens \\
exordium & $\begin{array}{l}\text { creator humanum rem publicam regendam distribuit, } \\
\text { propositum constat in commune justitiam colere, recta }\end{array}$ \\
& $\begin{array}{l}\text { judicare populisque subditis quibus imperant juste } \\
\text { consulere, dignum est et utile ut nos, quos ad regni } \\
\text { fastigium regum rex et omnium dominus dignatus est } \\
\text { attollere, ea quae sibi sunt placita debeamus cogitare... }\end{array}$ \\
& Quapropter noverit presentium futurorumque universitas \\
\hline
\end{tabular}

${ }_{28}$ Murphy, Rhetoric in the Middle Ages, $\mathbb{S V}$.

${ }^{29} \mathrm{KocH}$, "Urkunde, Brief und öffentliche Rede", p. 16. Koch toma el texto del Manuel de diplomatique française et pontificiale de Alain de Boüard, vol. 1, París, Auguste Picard, 1929 y 1948, pp. 257-259. 
Cuadro 1 (continúa)

\begin{tabular}{|c|c|}
\hline Partes & Texto \\
\hline Narratio & $\begin{array}{l}\text { quod fidelissimus noster Raynerius abba et monachi } \\
\text { monasterii ter beati Dyonisii martyris, peculiaris } \\
\text { patroni nostri, adierunt serentitatem nostram humiliter } \\
\text { obsecrantes ut, sicut antiqui et glorisissimi Francorum } \\
\text { reges }[\ldots . .] \text { usque ad nostra tempora ídem monasterium jam } \\
\text { predicti sancti decretorum suorum sanctionibus contra } \\
\text { iniquorum pervasionem muniverant atque episcoporum } \\
\text { et apostolicorum consensu et auctoritate postulatione } \\
\text { regia plenissime roborari poposcerant, ita nos, Dei nostri } \\
\text { voluntatem in omnibus sequentes et illos predecessores } \\
\text { nostros in hoc fideliter imitantes, nostram illi monasterio } \\
\text { adderemus, immo nostra sanctione illorum roboraremus... }\end{array}$ \\
\hline Dispositio & $\begin{array}{l}\text { Igitur fidelium nostrorum atque palatinorum usi consilio } \\
\text { et hoc prospicientes ipsi aecclesiae et habitantibus in } \\
\text { ea sive pertinentibus ad eam utile fore non solum in } \\
\text { presenti sed in futuro, regum seu imperatorum [...] } \\
\text { decreta sed et sancti Landerici, Parisiorum quondam } \\
\text { episcopi, privilegium et Gallicanorum episcoporum seu } \\
\text { apostolicorum Romanorum pontificum privilegia sancti et } \\
\text { egregii martyris Dyonisii monasterio olim indulta, per hanc } \\
\text { preceptionis nostre paginam DECERNIMUS in perpetuum } \\
\text { CONSERVANDA... }\end{array}$ \\
\hline Sanctio & $\begin{array}{l}\text { Si quis autem contra hanc preceptionis et auctoritatis } \\
\text { nostrae paginam senserit, quicumque ille fuerit, } \\
\text { cujuscumque nominis et honoris, etatis et potestatis, gradus } \\
\text { et ordinis, et eam vel in magno vel in minimo infringere } \\
\text { voluerit, et id quod cupit non efficiat et ad aerarium nostrae } \\
\text { domus XII }{ }^{\text {cim }} \text { libras ex auro purissimo coactus addat et } \\
\text { insuper reus majestatis habeatur et ut profanus ab omnibus, } \\
\text { nisi satis pro emendatione fecerit, computetur. }\end{array}$ \\
\hline Corroboratio & $\begin{array}{l}\text { Ut igitur hoc decretum a nobis promulgatum pleniorem } \\
\text { obtineat vigorem, nostra manu subter appositio signo } \\
\text { roboravimus atque fidelibus nostris presentibus } \\
\text { roborandum tradidimus nostraeque imaginis sigillo insuper } \\
\text { assignari jussimus. }\end{array}$ \\
\hline
\end{tabular}


Cuadro 1 (concluye)

\begin{tabular}{ll}
\hline Partes & Texto \\
\hline Subscriptiones & $\begin{array}{l}\text { (monogramma) Signum Philippi, incliti et } \dagger \text { serenissimi } \\
\text { Francorum regis. } \\
\text { (sigillum) Petrus, regiae dignitatis concellarius, relegit }\end{array}$ \\
& $\begin{array}{l}\text { et sigillavit. } \\
\text { Datum }\end{array}$ \\
& $\begin{array}{l}\text { Data Kal. Augusti, anno octavo regnante Phylippo rege, ab } \\
\text { incarnatione autem Domini millesimo LXvIII, indictione vi. } \\
\text { Actum Silnectis palatio regio. }\end{array}$ \\
Apprecatio & In Dei nomine feliciter, amen.
\end{tabular}

Tomado de Koch, “Urkunde...”, p. 16.

Estas secciones, a su vez, se organizaban en grandes grupos textuales: el protocolo, el cuerpo o texto y el escatocolo. Al respecto, para los documentos reales en la España medieval, los diversos analistas de la ciencia diplomática coinciden en el esquema general, como el que despliega Tamayo en su manual de Diplomática y que retomo aquí, aplicado a una provisión real castellana de 1442, ya escrita en castellano, que el propio Tamayo ofrece como ejemplo ${ }^{30}$ (cuadro 2). Algunas de estas partes, como las invocaciones del protocolo, no están incluidas. En el ejemplo, dentro de las cláusulas de garantía, he señalado entre corchetes aquellas referentes a las sanciones y a la corroboración del cumplimiento de las disposiciones.

Este modelo de las provisiones reales se mantuvo también durante el Renacimiento y sirvió para armar las disposiciones del derecho indiano. Éstas, de acuerdo con Alfonso García Gallo, ${ }^{31}$ se organizaban según la estructura textual de las provisiones

30 Tamayo, Archivística, diplomática y sigilografía, p. 289. Tamayo obtiene el documento del AHN., Secc. Clero, Fondo de Guadalupe, carp. 405, núms. 5-6. 31 García Gallo, "La ley como fuente del derecho en Indias en el siglo xvI"; véase también ReAL DíAz, Estudio diplomático del documento indiano. 


\section{Cuadro 2}

PROVISIÓN REAL DE JUAN II DE CASTILLA, DEL AÑO 1442

\begin{tabular}{|c|c|c|}
\hline $\begin{array}{l}\text { PARTES } \\
\text { GENERALES }\end{array}$ & $\begin{array}{l}\text { Partes } \\
\text { Del teXto }\end{array}$ & $\begin{array}{l}\text { Provisión real de Juan II de Castilla } \\
\text { dirigida a los alcaldes, otras autoridades } \\
\text { y almojarifes de Sevilla, ordenándoles } \\
\text { respeten y hagan respetar los privilegios } \\
\text { que venía disfrutando el Monasterio de } \\
\text { Santa María de Guadalupe (21 de febrero } \\
\text { de 1442). }\end{array}$ \\
\hline \multirow[t]{4}{*}{ Protocolo } & Invocaciones & ----- \\
\hline & Intitulación & $\begin{array}{l}\text { Don iohan por la graçia de dios rrey de } \\
\text { castila de león de Toledo de gallisia de } \\
\text { sevilla de cordova de murçia de jahen del } \\
\text { algarbe de algesira e señor de viscaya e de } \\
\text { molina, }\end{array}$ \\
\hline & Dirección & $\begin{array}{l}\text { A los mis alcaldes e alguasil e otras } \\
\text { justiçias qualesquier de la muy noble } \\
\text { çibdad de Sevilla e a los almoxarifes de la } \\
\text { dicha çibdad e a otras qualesquier personas } \\
\text { a quien tañe o tañer puede el negoçio yuso } \\
\text { escripto e a qualquier o qualesquier de vos } \\
\text { a quien esta carta fuere mostrada, }\end{array}$ \\
\hline & Salutación & salud e graçia, \\
\hline \multirow{3}{*}{$\begin{array}{l}\text { Cuerpo } \\
\text { o texto }\end{array}$} & Preámbulo & --- \\
\hline & Notificación & Sepades \\
\hline & Exposición & $\begin{array}{l}\text { quel prior e convento del monesterio de } \\
\text { santa maria de Guadalupe de la orden de } \\
\text { sant geronimo me enviaron faser rrelaçion } \\
\text { quellos han e tienen de los rreyes de } \\
\text { gloriosa memoria mis progenitores çiertos } \\
\text { previllejios e esençiones e franquesas e } \\
\text { libertades confirmadas de mi e que se } \\
\text { rreçelan que gelas non querredes guardar } \\
\text { vos o algunos de vos e lo qual si asi pasase } \\
\text { dis que ellos rreçeberian gran agravio } \\
\text { e danno e me pidieron por merçed que } \\
\text { sobre ello les proveyese del rremedio de } \\
\text { justicia commo la mi merçed fuese e yo } \\
\text { tovelo por bien }\end{array}$ \\
\hline
\end{tabular}




\section{Cuadro 2 (concluye)}

\begin{tabular}{|c|c|c|}
\hline \multirow[t]{2}{*}{$\begin{array}{l}\text { Cuerpo } \\
\text { o texto }\end{array}$} & Disposición & $\begin{array}{l}\text { por que vos mando a todos e a cada uno de } \\
\text { vos que veades los dichos previllejios que } \\
\text { en [e]sta rrason vos serán mostrados de } \\
\text { parte del dicho prior e convento del dicho } \\
\text { monesterio e los guardedes e cunplades } \\
\text { e fagades guardar e conplir en todo e por } \\
\text { todo segund que en [e]llos se contiene } \\
\text { e que non vayades nin pasedes nin } \\
\text { consyntades yr nin pasar contra ello nin } \\
\text { contra cosa alguna nin parte dello agora } \\
\text { nin en algund tiempo. }\end{array}$ \\
\hline & $\begin{array}{l}\text { Cláusulas de } \\
\text { garantía }\end{array}$ & $\begin{array}{l}\text { [Sanctio] E los unos nin los otros son } \\
\text { fagades ende al por alguna manera so pena } \\
\text { de la mi merçed e de diez mill maravedis } \\
\text { a cada uno por quien fincare de lo asi } \\
\text { faser e conplir para la mi camara. E demas } \\
\text { mando al omne que vos la mostrare que } \\
\text { vos enplase que parescades ante mi en la } \\
\text { mi corte do quier que yo sea del dia que } \\
\text { vos enplasare fasta quinse dias primeros } \\
\text { siguientes so la dicha pena a cada uno a } \\
\text { desir por qual rrason non conplides mi } \\
\text { mandado [Corroboratio] so la qual mando } \\
\text { a qualquier escrivano publico que para } \\
\text { esto fuere llamado que de ende al que vos } \\
\text { la mostrare testimonio signado con su } \\
\text { signo porque yo sepa en commo conplides } \\
\text { mi mandado. }\end{array}$ \\
\hline \multirow[t]{2}{*}{ Escatocolo } & Data & $\begin{array}{l}\text { Dada en la villa de benavente veynte e } \\
\text { un dias de febrero año del nasçimiento } \\
\text { del nuestro señor ihesu christo de mill e } \\
\text { quatroçientos e quarenta dos años.- }\end{array}$ \\
\hline & $\begin{array}{l}\text { Validación } \\
\text { [Suscripciones] }\end{array}$ & $\begin{array}{l}\text { Yo el dottor fernando dias de toledo oydor } \\
\text { e rreferendario del rrey e su secretario la } \\
\text { fise escribir por su mandado. } \\
\text { Yo el rrey. }\end{array}$ \\
\hline
\end{tabular}

Tomada de Tamayo, Archivística, p. 289. 
reales siguiente, que, de nuevo, guarda los cánones generales de los documentos medievales y renacentistas:

1) Las cláusulas iniciales
a) La intitulación o dictado
b) La dirección
c) La salutación

2) El texto o parte sustantiva
a) Notificación
b) Exposición
c) Cláusula de acuerdo o acordada
d) La decisión

3) Las cláusulas finales:
a) El requerimiento para que se cumpla la disposición
b) La cláusula que ordena la publicación de la disposición
c) La cláusula que establece penas a los infractores
d) La data, y
e) Las suscripciones

Según se deduce, las cláusulas iniciales corresponden al protocolo; la parte sustantiva, al cuerpo del texto, y algunas de las cláusulas finales, al escatocolo, particularmente, la data y las suscripciones, no así las cláusulas que establecen penas, las cuales, en el esquema de Tamayo, forman parte del cuerpo del texto. Un ejemplo de la estructura textual de las disposiciones indianas se observa en una provisión real castellana de Felipe II, suscrita en 1543, que recupero del Cedulario indiano de Diego de Encinas ${ }^{32}$ (cuadro 3). Como se observa en el cuadro, el orden de las cláusulas puede ser flexible. En esta provisión, el monarca establece varias disposiciones con sus penas correspondientes, en caso de

32 Encinas, Cedulario indiano, pp. 282-283. He acudido a este cedulario porque, a diferencia de algunas recopilaciones de derecho indiano, esta colección mantiene el texto completo de cada disposición, sin eliminar o abreviar de algunas de ellas las cláusulas de intitulación, dirección, notificación y exposición. 
Cuadro 3

PROVISIÓN REAL CASTELLANA DE FELIPE II DEL AÑO 1543

\begin{tabular}{|c|c|c|}
\hline $\begin{array}{l}\text { PARTES } \\
\text { GENERALES }\end{array}$ & $\begin{array}{l}\text { Partes DeL } \\
\text { TEXTO }\end{array}$ & Provisión real de Felipe II del año 1543 \\
\hline Inicial & Intitulación & Don Felipe, \&c. \\
\hline Inicial & Dirección & $\begin{array}{l}\text { A vos los nueftros Viforreyes, Prefidente } \\
\text { y Oydores de las nueftras audiencias y } \\
\text { chancillerias Reales de las nueftras Indias, } \\
\text { iflas y Tierrafirme del mar Oceano, y } \\
\text { nueftros Gouernadores y Alcaldes y otros } \\
\text { juezes y jufticias qualefquier, de todas } \\
\text { las ciudades, villas y lugares delas dichas } \\
\text { nueftras Indias, islas y Tierrafirme del mar } \\
\text { Oceano, e a cada vno y qualquier de vos } \\
\text { en vueftros lugares y juridiciones, a quien } \\
\text { efta nueftra carta fuere moftrada, o fu } \\
\text { traflado fignado de efcriuano publico, }\end{array}$ \\
\hline Inicial & Salutación & falud y gracia. \\
\hline Sustantiva & Notificación & Sepades que \\
\hline Sustantiva & Exposición & $\begin{array}{l}\text { nos fomos informados que los Efpañoles } \\
\text { y perfonas que refiden en las dichas } \\
\text { nueftras Indias, quando vienen dellas a } \\
\text { eftos Reynos, traen a ellos muchos Indios } \\
\text { e Indias naturales deffas parte, vnos con } \\
\text { color de licencias generales que hemos } \\
\text { dado a algunas prouincias, e otras perfonas } \\
\text { particulares, e otros que fe los aueis dado } \\
\text { vos los gouernadores e jufticias, e otros } \\
\text { con color que dizen que los dichos Indios } \\
\text { fe quieren venir de fu voluntad, y otros } \\
\text { pretendiendo que fon fus efclavos. Lo qual } \\
\text { demas del inconueniente grande que fe } \\
\text { figue a la poblacion de las dichas Indias, } \\
\text { por facar dellas fus naturales, fe ha vifto } \\
\text { por experiencia que antes que llegan a eftos } \\
\text { Reynos y defpues de llegados a ellos, los } \\
\text { dichos Indios fe mueren, por fer diferentes } \\
\text { las calidades de las partes donde paffan, }\end{array}$ \\
\hline
\end{tabular}


Cuadro 3 (continúa)

\begin{tabular}{|c|c|c|}
\hline $\begin{array}{l}\text { PARTES } \\
\text { GENERALES }\end{array}$ & $\begin{array}{l}\text { Partes Del } \\
\text { TEXTo }\end{array}$ & Provisión real de Felipe II del año 1543 \\
\hline Sustantiva & Exposición & $\begin{array}{l}\text { y deftos Reynos a fus naturalezas, y fer } \\
\text { ellos de flaca complefion: y demas defto } \\
\text { falidos de poder de las perfonas que los } \\
\text { traen, fe pierden por no tener induftria } \\
\text { de ganar de comer en eftas partes, y fe } \\
\text { han feguido y liguen otros muchos daños } \\
\text { e inconuenientes en detrimento de las } \\
\text { perfonas y vidas de los dichos Indios e } \\
\text { Indias, de que Dios nueftro Señor y nos } \\
\text { auemos fido y fomos deferuidos. }\end{array}$ \\
\hline Sustantiva & $\begin{array}{l}\text { Cláusula } \\
\text { acordada }\end{array}$ & $\begin{array}{l}\text { Y queriendo proueer en el remedio dello, } \\
\text { para que de aqui adelante ceffen, viffto } \\
\text { y platicado en el nueftro Confejo de } \\
\text { las Indias, fue acordado que deuiamos } \\
\text { mandar dar efta nueftra carta en la dicha } \\
\text { razon, e nos tuuimoflo por bien. }\end{array}$ \\
\hline Sustantiva & Decisión & $\begin{array}{l}\text { Por la qual prohibimos y efpreffamente } \\
\text { defendemos, que de aqui adelante ninguna } \\
\text { ni algunas perfonas, vezinos, eftantes y } \\
\text { abitantes en las dichas nueftras Indias, } \\
\text { islas y Tierrafirme del mar Oceano, } \\
\text { de qualquier eftado y calidad y condicion } \\
\text { que fean, no fean ofados a traer ni } \\
\text { embiar de las dichas nueftras Indias, } \\
\text { Indios ni Indias algunas, aunque tengan } \\
\text { licencia nueftra para ello, o de nueftros } \\
\text { gouernadores e jufticias, agora fea de } \\
\text { los que pretendieren tener derecho por } \\
\text { efclauos, y verdaderamente lo fueren, o } \\
\text { de los que fueren libres, no embargante } \\
\text { que los dichos Indios e Indias digan que } \\
\text { fe quieren venir con ellos de fu voluntad, } \\
\text { y que fea afsi, }\end{array}$ \\
\hline
\end{tabular}




\section{Cuadro 3 (continúa)}

\begin{tabular}{|c|c|c|}
\hline $\begin{array}{l}\text { PARTES } \\
\text { GENERALEs }\end{array}$ & $\begin{array}{l}\text { PARTES DEL } \\
\text { TEXTO }\end{array}$ & Provisión real de Felipe II del año 1543 \\
\hline Final & $\begin{array}{l}\text { Cláusula que } \\
\text { establece penas }\end{array}$ & $\begin{array}{l}\text { fo pena que qualquiera perfona que } \\
\text { contra el tenor y forma defta nueftra } \\
\text { carta traxeren o embiaren Indias o Indios } \\
\text { algunos, libres o efclauos, de las dichas } \\
\text { nueftras Indias, o dieren confentimiento, } \\
\text { favor o ayuda a ello, caygan en pena de } \\
\text { cien mil marauedis, la qual fe reparta en } \\
\text { efta manera, la tercia parte para nueftra } \\
\text { camara y fifco, y las otras dos tercias partes } \\
\text { para el acufador y juez que lo fentenciare: } \\
\text { y demas de la dicha pena, incurran los que } \\
\text { contra efta nueftra carta paffaren, en pena } \\
\text { de deftierro perpetuo de las dichas nueftras } \\
\text { Indias, y demas que a fu cofta fean bueltos } \\
\text { a las prouincias o Indias donde los ouieren } \\
\text { facado. En las quales dichas penas a los } \\
\text { que en ellas incurrieren, los condenamos y } \\
\text { auemos por condenados, y mandamos que } \\
\text { fean executados en fus perfonas y bienes, } \\
\text { fin otra fentencia ni declaracion alguna, lin } \\
\text { embargo de qualefquier licencias generales } \\
\text { o particulares que ayamos dado para traer } \\
\text { los dichos Indios. }\end{array}$ \\
\hline Sustantiva & Decisión & $\begin{array}{l}\text { Las quales nos por la prefente reuocamos } \\
\text { y damos por ningunas y de ningun valor } \\
\text { y efecto. }\end{array}$ \\
\hline Final & $\begin{array}{l}\text { Cláusulas que } \\
\text { establecen } \\
\text { penas }\end{array}$ & $\begin{array}{l}\text { Y la perfona que viniere y paffare contra } \\
\text { lo fufo dicho, fino tuuiere bienes en que } \\
\text { fe pueda executar la pena de los cien mil } \\
\text { marauedis, mandamos que le fean dados } \\
\text { cien açotes publicamente, en qualquier } \\
\text { parte donde fuere tomado, demas del } \\
\text { dicho deftierro. }\end{array}$ \\
\hline
\end{tabular}


Cuadro 3 (continúa)

\begin{tabular}{|c|c|c|}
\hline $\begin{array}{l}\text { Partes } \\
\text { GENERALES }\end{array}$ & $\begin{array}{l}\text { Partes Del } \\
\text { TEXTO }\end{array}$ & Provisión real de Felipe II del año 1543 \\
\hline Sustantiva & Decisión & $\begin{array}{l}\text { Y anfimifmo prohibimos y mandamos } \\
\text { a vos los dichos nueftros Viforreyes, } \\
\text { Prefidentes y Oydores y nueftros } \\
\text { gouernadores y jufticias de las dichas } \\
\text { nueftras Indias, que agora ni en ningun } \\
\text { tiempo no deis licencia alguna, para traer } \\
\text { deffas partes a eftos Reynos, Indias ni } \\
\text { Indios algunos, efclavos ni libres, }\end{array}$ \\
\hline Final & $\begin{array}{l}\text { Cláusulas que } \\
\text { establecen } \\
\text { penas }\end{array}$ & $\begin{array}{l}\text { fo pena de priuacion de vueftros oficios, } \\
\text { no embargante qualefquier cedulas } \\
\text { nueftras que os fean prefentadas, en que } \\
\text { os mandamos que deictas dichas licencias, } \\
\text { anfi generales como particulares: }\end{array}$ \\
\hline Sustantiva & Decisión & $\begin{array}{l}\text { las quales nos como dicho es reuocamos y } \\
\text { damos por ningunas y de ningun valor y } \\
\text { efecto, }\end{array}$ \\
\hline Final & $\begin{array}{l}\text { Requerimiento } \\
\text { para que se } \\
\text { cumpla la } \\
\text { disposición }\end{array}$ & $\begin{array}{l}\text { porque vos mandamos a todos y a cada } \\
\text { vno de vos en vueftra juridicion fegun } \\
\text { dicho es, que anfi lo guardeis, cumplais } \\
\text { y executeis en todo y por todo, en las } \\
\text { perfonas y bienes de los que contra ello } \\
\text { y parte dello fueren y paffaren teniendo } \\
\text { dello muy efpecial cuidado, como de cofa } \\
\text { importante al feruicio de Dios nueftro } \\
\text { Señor y nueftro, y bien de los naturales } \\
\text { deflas partes y poblacion dellos. }\end{array}$ \\
\hline Final & $\begin{array}{l}\text { Cláusula que } \\
\text { ordena la } \\
\text { publicación de } \\
\text { la disposición }\end{array}$ & $\begin{array}{l}\text { Y porque lo fufodicho fea publico } \\
\text { y notorio a todos y ninguno pueda } \\
\text { pretender ignorancia, mandamos que efta } \\
\text { nueftra carta fea pregonada publicamente } \\
\text { en las ciudades villas y lugares deffas } \\
\text { partes, por pregonero y ante efcriuano } \\
\text { publico: }\end{array}$ \\
\hline
\end{tabular}


Cuadro 3 (concluye)

\begin{tabular}{|c|c|c|}
\hline $\begin{array}{l}\text { PARTES } \\
\text { GENERALES }\end{array}$ & $\begin{array}{l}\text { Partes DeL } \\
\text { TEXTO }\end{array}$ & Provisión real de Felipe II del año 1543 \\
\hline Final & $\begin{array}{l}\text { Cláusula que } \\
\text { establece pena }\end{array}$ & $\begin{array}{l}\text { e los vnos ni los otros no fagades ni fagan } \\
\text { ende al por alguna manera fo las dichas } \\
\text { penas. }\end{array}$ \\
\hline Final & Data & $\begin{array}{l}\text { Dada en la villa de Valladolid, a veinte y } \\
\text { ocho de Setiembre, de mil y quinientos } \\
\text { quarenta y tres años }\end{array}$ \\
\hline Final & Suscripciones & $\begin{array}{l}\text { Yo el Principe. Yo Iuan de Samano } \\
\text { fecretario de fus Catolicas Magestades la } \\
\text { fize efcriuir por fu mandado de fu Alteza. } \\
\text { Epifcopus Oxomenf. Doctor Bernal. } \\
\text { El Licenciado Gutierre Velazquez. El } \\
\text { Licenciado Gregorio Lopez. El Licenciado } \\
\text { Salmeron. Regiftrada, Ochoa de Luyand. } \\
\text { Por Chanciller, Blas de Saauedra. }\end{array}$ \\
\hline
\end{tabular}

Tomada de Encinas, Cedulario indiano, pp. 282-283.

no cumplirse, de tal manera que puede haber elementos sustantivos o del cuerpo del texto intercalados con tales cláusulas finales.

$\mathrm{Al}$ retomar los moldes textuales diplomáticos entre los siglos XI y XVI, se obtiene la siguiente comparación de las partes textuales de los tres documentos ejemplares mostrados (cuadro 4). Este cuadro comparativo, además de destacar las similitudes entre estos moldes textuales, también sirve para comprobar que estamos frente a una misma línea de tradiciones discursivas adoptadas para los ordenamientos jurídicos monárquicos europeos que seguían los cánones del derecho romano y de la jurisprudencia que integraba en sus amplísimas argumentaciones el saber, la práctica, las reflexiones y los ordenamientos del derecho antiguo, amén de la amplitud de tipos textuales que se generaron durante este largo periodo, que no necesariamente siguieron este canon. Lo que se observa es la permanencia de una tradición de raigambre milenaria. 


\section{Cuadro 4}

COMPARACIÓN DE LAS PARTES DEL DOCUMENTO

DIPLOMÁTICO MEDIEVAL, DEL DOCUMENTO CASTELLANO

Y DEL DOCUMENTO INDIANO

\begin{tabular}{|c|c|c|}
\hline $\begin{array}{l}\text { EL DOCUMENTO } \\
\text { DIPLOMÁTICO- } \\
\text { RETÓRICO } \\
\text { (Edad Media) } \\
\end{array}$ & $\begin{array}{l}\text { Provisión REAL } \\
\text { CASTELLANA } \\
\text { (Edad Media y } \\
\text { Renacimiento) } \\
\end{array}$ & $\begin{array}{l}\text { EL DOCUMENTO } \\
\text { INDIANO } \\
\text { (siglos XVI-XVIII) }\end{array}$ \\
\hline $\begin{array}{l}\text { Invocatio, Intitulatio, } \\
\text { Inscriptio, Salutatio }\end{array}$ & $\begin{array}{l}\text { Intitulación, Dirección, } \\
\text { Salutación }\end{array}$ & $\begin{array}{l}\text { Intitulación, Dirección, } \\
\text { Salutación }\end{array}$ \\
\hline $\begin{array}{l}\text { Arenga/Exordium, } \\
\text { Narratio }\end{array}$ & $\begin{array}{l}\text { Notificación, } \\
\text { Exposición }\end{array}$ & $\begin{array}{l}\text { Notificación, } \\
\text { Exposición, Cláusula } \\
\text { acordada }\end{array}$ \\
\hline \multicolumn{3}{|l|}{ Promulgatio } \\
\hline Dispositio & Disposición & Decisión \\
\hline Sanctio, Corroboratio & $\begin{array}{l}\text { Cláusulas de garantía } \\
\text { (Sanctio, Corroboratio) }\end{array}$ & $\begin{array}{l}\text { Sanción, Orden de } \\
\text { cumplimiento, Orden } \\
\text { de publicación }\end{array}$ \\
\hline $\begin{array}{l}\text { Subscriptiones, Datum, } \\
\text { Apprecatio }\end{array}$ & $\begin{array}{l}\text { Data, Validación } \\
\text { (Suscripciones) }\end{array}$ & Data, Suscripciones \\
\hline
\end{tabular}

Además, se trata de una tradición discursiva supraidiomática, porque esta estructura textual sirve para los documentos escritos en latín o en las lenguas vernáculas europeas. Se observa también que la argumentación, presente en las secciones de la exposición, de la narración, incluso de la sanción, iba vinculada discursiva y sintácticamente con el centro jurídico de cada documento, esto es, con la decisión, y que, desde la perspectiva de la retórica clásica, se expresaba a modo de conclusión de dicha exposición de motivos.

Ello se comprueba con el uso de los nexos igitur, por que y por la qual que introducen las decisiones principales del rey Felipe I de Francia (1068), el rey Juan II de Castilla (1442) y el 


\section{Cuadro 5}

NEXOS SINTÁCTICO-DISCURSIVOS ENTRE LA EXPOSITIO

Y LA DISPOSITIO EN TRES DOCUMENTOS DIPLOMÁTICOS

\begin{tabular}{|c|c|c|}
\hline $\begin{array}{l}\text { DiPLOMA REAL DE } \\
\text { FELIPE I DE FRANCIA } \\
\text { (IO68) }\end{array}$ & $\begin{array}{l}\text { Provisión REAL de } \\
\text { JuAn II de CASTILla } \\
(\mathrm{I} 442)\end{array}$ & $\begin{array}{l}\text { PROVISIÓN REAL } \\
\text { INDIANA DE FELIPE DE } \\
\text { ASTURIAS (I } 543 \text { ) }\end{array}$ \\
\hline $\begin{array}{l}\text { Igitur }[\ldots] \text {, per hanc } \\
\text { preceptionis nostre } \\
\text { paginam } D E C E R N I M U S \\
\text { in perpetuum } \\
\text { CONSERVANDA }[\ldots]\end{array}$ & $\begin{array}{l}\text { por que vos MANDO a } \\
\text { todos e a cada uno de } \\
\text { vos que }[\ldots]\end{array}$ & $\begin{array}{l}\text { Por la qual PROHIBIMOS } \\
\text { y efpreffamente } \\
\text { DEFENDEMOS, que }[. . .]\end{array}$ \\
\hline
\end{tabular}

príncipe Felipe de Asturias (1543), respectivamente, en las disposiciones que he empleado aquí como ejemplos (cuadro 5).

En cuanto al derecho indiano, de acuerdo con Víctor Tau Anzoátegui, ${ }^{33}$ la exposición de motivos de cada ley cobró especial relevancia, sobre todo para justificar asuntos polémicos tales como la propia política indiana y la conquista. La exposición de motivos era una razón pública de una decisión legislativa. En el siglo XVI - parafrasea Tau Anzoátegui a García Gallo ${ }^{34}$ - y -agrego- en la misma línea de la tradición jurídica medieval,

[...] la exposición de motivos y la disposición eran esenciales de la ley e integraban la parte central de la misma. Aquella raramente faltaba y era más bien la expresión de los antecedentes que de la intención o fines perseguidos. No era meramente informativa, sino que buscaba acreditar la necesidad de la nueva ley y suministraban [sic] elementos para mostrar su racionalidad. ${ }^{35}$

33 Tau Anzoátegui, “Acerca de la elaboración y publicación”, pp. 157-181. 34 García Gallo, "La ley como fuente del derecho en Indias en el siglo xvi”, pp. 228-229.

35 Tau Anzońtegui, “Acerca de la elaboración y publicación”, p. 167. 
Pero, a diferencia de la sección deliberativa, durante el siglo xviII, la exposición de motivos dejó de integrarse en la redacción de las leyes. Tau Anzoátegui cita la disposición del Consejo de Indias del 15 de julio de 1755 de no incluir en las cédulas "las razones o fundamentos que motivan sus resoluciones" ${ }^{36}$ De todas formas, se mantiene el ingrediente argumentativo, pues se expresaban "las relaciones de las partes o las causas que las originan". ${ }^{37}$ Según este autor, el absolutismo desmedido de las últimas décadas del siglo xvirı llevó a un cambio en el estilo de las leyes, que produjo "textos desnudos de toda razón o motivos, que no admitían réplica ni súplica y en los que se imponía un aire de superioridad hacia los ministros destinatarios de las provincias indianas". ${ }^{38}$ Tal estilo se trasminó a los niveles jurisdiccionales locales.

\section{De las disposiciones jurídicas indianas} a los códigos y las leyes especiales

La tradición codificadora es resultado de la era de las revoluciones intelectuales del siglo xviII. Forma parte de los procesos de la secularización del Derecho, la glorificación del Estado, el nacionalismo, el nuevo concepto de soberanía, la separación de los poderes del Estado, el carácter natural de los derechos del hombre, el racionalismo y el liberalismo antifeudal. De todo este escenario, sin embargo, Paolo Grossi ${ }^{39}$ nos revela el núcleo de la profunda transformación para una historia milenaria del derecho. Se trata de la monopolización del Estado de las fuentes del derecho, que las reduce a una sola: la norma o, mejor dicho, un sistema jerarquizado de normas abstractas y ahistórico, por su pretensión universalista, materializado en un

36 Tau Anzó́tegui, “Acerca de la elaboración y publicación”, p. 168.

37 Tau Anzó́tegui, “Acerca de la elaboración y publicación”, p. 168.

38 TAu Anzó́tegui, “Acerca de la elaboración y publicación”, p. 169.

39 Grossi, De la codificación a la globalización del derecho, pp. 53-86. 
conjunto de leyes escritas, cuyo modelo textual por excelencia será el código moderno del siglo xIX y cuyo arquetipo será el Código Civil de los franceses (1804) o el Code Napoléon (1807). En palabras de Grossi:

[S]i en la sociedad medieval y posmedieval del pasado, en el seno de una civilización sin Estado, se admitía (y valoraba) una pluralidad de fuentes del derecho -esto es, al lado de la ley del Príncipe se encontraban, en una posición más relevante, las costumbres, la ciencia jurídica, la jurisprudencia de los jueces-, la sociedad moderna, cada vez más constreñida por el nudo corredizo del Estado, tiende, con cada vez más intensidad, a identificar el derecho con la ley. ${ }^{40}$

No es difícil entender que este vuelco jurídico fuera adoptado como un ideal en las nuevas naciones americanas que comenzaban a gestarse desde la primera década del siglo xIx. En la misma línea, haciendo eco de las ideas de Grossi, Jaime del Arenal explica este relevo de paradigmas jurídicos tomando en cuenta también el mundo latinoamericano. De acuerdo con él, la pretensión por parte del Estado de ser el ordenador único de la ley y de que ésta fuera la única fuente del derecho, en detrimento de todas las demás, sobre todo, de la jurisprudencia, base del ius commune que había imperado a lo largo de la Edad Media, arrastró consecuencias devastadoras para las leyes tradicionales:

[S]i antes se pudieron concebir leyes particulares, ancladas a circunstancias concretas y específicas por las diferencias histórico culturales existentes entre sociedades y pueblos de muy diversos orígenes (el mejor ejemplo estaría en el Derecho Indiano), ahora la definición de las leyes científicas influyó en la de las leyes jurídicas: mandamientos generales, universales y permanentes, unidos todos dentro de un sistema que refleja el propio sistema del universo,

${ }^{40}$ Grossi, Elnovecientos jurídico: un siglo posmoderno, pp. 18-19. 
donde cada partícula o elemento singular encuentra su referente con un principio abstracto y universal, general y permanente. ${ }^{41}$

Los efectos discursivos y textuales en la expresión de las leyes se antojan también radicales. El iusnaturalismo racionalista dictaba con toda explicitud que las leyes habrían de formularse realmente como las leyes naturales y en un estilo llano, comprensible para cualquier ciudadano de a pie y libres de cualquier argumentación retórica, como era propio de las disposiciones medievales, sobre todo de la expositio, cuya consecuencia lógica era la dispositio como tal. Por ejemplo, Montesquieu escribía en De l'ésprit des lois (1757) máximas como las siguientes:

Le style des lois doit être simple; l'expression directe s'entend toujours mieux que l'expression réfléchie. Il n'y a point de majesté dans les lois du bas empire; on y fait parler les princes comme des rhéteurs. Quand le style des lois est enflé, on ne les regarde que comme un ouvrage d'ostentation. ${ }^{42}[\ldots]$ Les lois ne doivent point être subtiles ; elles sont faites pour des gens de mediocre entendement : elles ne sont point un art de logique, mais la raison simple d'un père de famille. ${ }^{43}$

Cabe ahora preguntarse: el cambio radical en la historia del derecho que se dio a fines del siglo xviII y que inauguró el nuevo paradigma de la codificación, que se expandió por Europa, América y algunos países asiáticos a lo largo del siglo xIx y que significó -al menos en términos ideológicos- la erradicación del ius commune medieval, ¿dio lugar también a un cambio radical en los moldes textuales de las disposiciones jurídicas? En otras palabras, la transformación de las tradiciones jurídicas

${ }^{41}$ Arenal Fenochio, Historia minima del derecho en Occidente, p. 149.

${ }^{42}$ Montesquieu, De l'ésprit des lois, pp. 292-293.

${ }_{43}$ Montesquieu, De l'ésprit des lois, p. 294. 
de dicho periodo, ¿provocó también un cambio en las tradiciones discursivas y, por ende, en las tradiciones textuales de las disposiciones jurídicas?

Podríamos pensar que el modelo textual de la era de la codificación cambió por completo respecto del de los diplomas reales europeos de los siglos XI al xvi que revisamos en el $\$ 3.1$, supra. Aunque en el México del siglo xix la mayor parte de las leyes emitidas no eran códigos, se esperaría que los que se promulgaron ya en la tradición jurídica codificadora mostraran una separación entre la exposición y el código como tal. En los códigos por materia (civiles, penales, comerciales, militares, etc.) y en cualquier ley articulada de la era moderna (desde las constituciones nacionales hasta las leyes y reglamentos), en efecto, no es común encontrar vínculos sintáctico-discursivos que concatenen las secciones del modelo documental medieval y renacentista. Además de la sistematización normativa articulada, organizada en capítulos y éstos en títulos, más la ausencia de preámbulos o justificaciones argumentativas para cada norma, una ley codificada se nos presenta como un texto independiente en el que todo se contiene. Sin embargo, tenemos que ver esto con más detenimiento. En el Estado moderno, para que una ley cobre vigencia y comience a funcionar en el mundo positivo del derecho, ésta ha de ser promulgada, decretada, publicada y difundida por los medios oficiales que el propio poder estatal establezca. ${ }^{44}$ Veamos cómo decretó Benito Juárez el Código Civil para el Distrito Federal y Baja California el 13 de diciembre

${ }^{44}$ Así, por ejemplo, Felipe Tena Ramírez define como sigue el acto de la promulgación de una ley en México: "Un acto por el que el Ejecutivo autentifica implícitamente la existencia y regularidad de la ley [...] y ordena expresamente que la ley se publique y sea cumplida". Tena Ramírez, Derecho constitucional mexicano, $\$ 145$, p. 462). De hecho, todas las constituciones mexicanas, desde la de 1824, y siguiendo la tradición de la Constitución de Cádiz (1812), normaron la promulgación por parte del Poder Ejecutivo de las leyes expedidas por el Congreso: en la de 1824, en el artículo 111; en la de 1836, en el 41; en la de 1857, en el 87, y en la de 1917, en el 70. 
de 1870. En el Cuadro 6 identifico en las dos primeras columnas las partes de la provisión real indiana con las partes del decreto decimonónico, ${ }^{45}$ que se despliegan en la tercera columna.

Se observa que el Código civil está contenido en el decreto o, cuando menos, presupone su existencia material en el artículo primero de dicho decreto; pero sólo a partir de la publicación de éste, el Código civil cobra vigencia jurídica. Desde el punto de vista textual, la diferencia primordial entre la tradición medieval y la tradición codificadora es la desvinculación sintáctico-discursiva entre las cláusulas precedentes a la disposición jurídica central y la ley decretada, por un lado, en términos de la inexistencia de nexos sintácticos entre ellos y, por otro, en términos retóricos, de la inexistencia de un vínculo argumentativo entre la exposición de motivos que dio lugar a la ley y la ley como tal.

Al menos, éste era el ideal textual, pues a lo largo del siglo XIX un buen número de disposiciones legislativas mexicanas no presentaron esta estructura textual, sino que resultaron en un híbrido entre el modelo retórico y el modelo articulado, porque solían incluir breves o largas exposiciones de motivos vinculadas sintácticamente a la cláusula de notificación y discursivamente introductorias de la decisión formulada a modo de artículos numerados. De acuerdo con los hallazgos de Vázquez Laslop (v. \ “Moldes textuales...", supra y nn. 1 y 23) en la revisión de la colección legislativa de Dublán y Lozano, ${ }^{46}$ se comprueba que, de un total de 10989 predicados directivos en disposiciones legislativas generadas entre 1821 y 1876, 40\% (4359 predicados) formaban parte de un texto legal con una sección de argumentación, en buena medida, vinculada discursiva o sintácticamente a dicho predicado. Quiere decir que la exposición de motivos y la ley como tal formaban parte de un mismo documento. Un

45 Tomado de Dublán y Lozano, Legislación mexicana, disposición número 6855, t. XI, pp. 201-449.

46 Dublán y Lozano, Legislación mexicana. 


\section{Cuadro 6}

DECRETO DE PROMULGACIÓN DEL CÓDIGO CIVIL MEXICANO (1870) Y LAS PARTES TEXTUALES DEL DOCUMENTO INDIANO

\begin{tabular}{|c|c|c|}
\hline $\begin{array}{l}\text { PARTES } \\
\text { GENERALES }\end{array}$ & $\begin{array}{l}\text { Partes textuales } \\
\text { DeL Documento } \\
\text { INDiano }\end{array}$ & $\begin{array}{l}\text { Decreto: Código civil para el D.F. } \\
\text { y Baja California (13 de diciembre } \\
\text { de 1870) }\end{array}$ \\
\hline $\begin{array}{l}\text { Cláusulas } \\
\text { iniciales }\end{array}$ & Intitulación & $\begin{array}{l}\text { Benito Juárez, presidente } \\
\text { constitucional de los Estados } \\
\text { Unidos Mexicanos, }\end{array}$ \\
\hline \multirow{4}{*}{$\begin{array}{l}\text { Texto o parte } \\
\text { sustantiva }\end{array}$} & Dirección & á sus habitantes, \\
\hline & Notificación & sabed: \\
\hline & Promulgación & $\begin{array}{l}\text { Que el congreso de la Union ha } \\
\text { tenido á bien decretar lo siguiente: }\end{array}$ \\
\hline & Decisión & $\begin{array}{l}\text { Art. 1. Se aprueba el Código Civil } \\
\text { [...] } \\
\text { El Código á que se refiere el } \\
\text { decreto anterior, es el siguiente: } \\
\text { Codigo civil } \\
\text { Titulo preliminar } \\
\text { De la ley y sus efectos, con las reglas } \\
\text { generales de su aplicacion. } \\
\text { Art. } 1 . \text { La ley civil es igual para } \\
\text { todos }[\ldots]\end{array}$ \\
\hline $\begin{array}{l}\text { Cláusulas } \\
\text { finales }\end{array}$ & $\begin{array}{l}\text { Orden de } \\
\text { publicación, Orden } \\
\text { de cumplimiento, } \\
\text { Data, Suscripciones }\end{array}$ & $\begin{array}{l}\text { Por tanto, mando se imprima, } \\
\text { publique, circule y se le dé el debido } \\
\text { cumplimiento. Palacio del gobierno } \\
\text { nacional en México, á } 13 \text { de } \\
\text { Diciembre de 1870.-Benito Juárez. }\end{array}$ \\
\hline
\end{tabular}

ejemplo de ello es el siguiente decreto de $1840^{47}$ (cuadro 7), en el que la exposición de motivos es complemento directo oracional de la notificación sabed, ligada a este predicado por el nexo

47 Tomado de Dublán y Lozano, Legislación mexicana, disposición número 2146, t. III, p. 738. 
subordinante que; a su vez, dicha exposición introduce como contenido de su objeto directo, lo siguiente, la decisión articulada, elementos que destaco en cursivas:

\section{Cuadro 7}

UN DECRETO DE 1840 Y LAS PARTES TEXTUALES

DEL DOCUMENTO INDIANO

\begin{tabular}{|c|c|}
\hline $\begin{array}{l}\text { PARTES TEXTUALES } \\
\text { DEL DOCUMENTO } \\
\text { INDIANO }\end{array}$ & $\begin{array}{l}\text { Ley.- Se establece una Escuela de aplicación } \\
\text { para la artillería, ingenieros y plana mayor } \\
\text { (11 de septiembre de 1840). }\end{array}$ \\
\hline Intitulación & El presidente de la república mexicana, \\
\hline Dirección & á los habitantes de ella, \\
\hline Notificación & sabed: \\
\hline Exposición & $\begin{array}{l}\text { Que deseando mejorar el servicio de los cuerpos } \\
\text { de artillería, ingenieros y de plana mayor del } \\
\text { ejército, en uso de la facultad que le concede el } \\
\text { decreto de } 13 \text { de Junio de } 1838 \text {, he decretado lo } \\
\text { siguiente: }\end{array}$ \\
\hline Decisión & $\begin{array}{l}\text { Art. } 1 \text {. Se establece una escuela de aplicación para } \\
\text { los capitanes y tenientes de artillería, ingenieros y } \\
\text { plana mayor del ejército. [...] }\end{array}$ \\
\hline
\end{tabular}

Más aún, según la costumbre de la diplomática medieval castellana, la cláusula de notificación sabed se conjugaba de acuerdo con el paradigma castellano de segunda persona plural vosotros, que en tal dialecto sigue siendo común hasta nuestros días como el plural de la forma tuteante. En el dialecto mexicano, no obstante, el paradigma gramatical correspondiente a vosotros evoca un estilo arcaizante y altamente solemne, inclusive en el siglo XIX, pero nunca asentado en el uso cotidiano del español mexicano. ${ }^{48}$

48 Vázquez Laslop y Orozco, "Formas de tratamiento del español en México", p. 257. 


\section{Cuadro 8}

DECRETO DE PROMULGACIÓN DEL CÓDIGO CIVIL MEXICANO (1928) Y LAS PARTES TEXTUALES DEL DOCUMENTO INDIANO

\begin{tabular}{|c|c|c|}
\hline $\begin{array}{l}\text { PARTES } \\
\text { GENERALES }\end{array}$ & $\begin{array}{l}\text { PARTES TEXTUALES } \\
\text { DEL DOCUMENTO } \\
\text { INDIANO }\end{array}$ & $\begin{array}{l}\text { Decreto: Código civil federal, } 30 \\
\text { de agosto de 1928. (Publicado en el } \\
\text { Diario Oficial de la Federación en } \\
\text { cuatro partes los días } 26 \text { de mayo, } 14 \\
\text { de julio, } 3 \text { y } 31 \text { de agosto de 1928.) }\end{array}$ \\
\hline \multirow[t]{2}{*}{$\begin{array}{l}\text { Cláusulas } \\
\text { iniciales }\end{array}$} & Intitulación & $\begin{array}{l}\text { Plutarco Elías Calles, } \\
\text { Presidente Constitucional de los } \\
\text { Estados Unidos Mexicanos, }\end{array}$ \\
\hline & Dirección & a sus habitantes, \\
\hline \multirow{5}{*}{$\begin{array}{l}\text { Texto o parte } \\
\text { sustantiva }\end{array}$} & Notificación & sabed: \\
\hline & Exposición & $\begin{array}{l}\text { Que en uso de la facultad que ha } \\
\text { tenido a bien conferirme el H. } \\
\text { Congreso de la Unión por Decretos } \\
\text { de } 7 \text { de enero y de } 6 \text { de diciembre de } \\
1926 \text { y de } 3 \text { de enero de } 1928 \text {, }\end{array}$ \\
\hline & Decisión & $\begin{array}{l}\text { expido el signiente } \\
\text { CODDIGO CIVIL FEDERAL }\end{array}$ \\
\hline & & Disposiciones Preliminares \\
\hline & & $\begin{array}{l}\text { Artículo 1o.- Las disposiciones } \\
\text { de este Código regirán en toda la } \\
\text { República en asuntos del orden } \\
\text { federal. } \\
{[\ldots]}\end{array}$ \\
\hline \multirow[t]{2}{*}{$\begin{array}{l}\text { Cláusulas } \\
\text { finales }\end{array}$} & $\begin{array}{l}\text { Orden de } \\
\text { publicación, Orden } \\
\text { de cumplimiento, } \\
\text { Data, Suscripciones }\end{array}$ & $\begin{array}{l}\text { Por tanto, mando se imprima, } \\
\text { publique, circule y se le dé el debido } \\
\text { cumplimiento. }\end{array}$ \\
\hline & & $\begin{array}{l}\text { Dado en el Palacio del Poder } \\
\text { Ejecutivo Federal, en México, a los } \\
\text { treinta días del mes de agosto de mil } \\
\text { novecientos veintiocho. - P. Elías } \\
\text { Calles.- Rúbrica.- El Secretario } \\
\text { de Estado y del Despacho de } \\
\text { Gobernación, Emilio Portes Gil.- }\end{array}$ \\
\hline
\end{tabular}


Cuadro 8 (concluye)

\begin{tabular}{|c|c|c|}
\hline $\begin{array}{l}\text { PARTES } \\
\text { GENERALES }\end{array}$ & $\begin{array}{l}\text { PARTES TEXTUALES } \\
\text { DEL DOCUMENTO } \\
\text { INDIANO }\end{array}$ & $\begin{array}{l}\text { Decreto: Código civil federal, } 30 \\
\text { de agosto de } 1928 . \text { (Publicado en el } \\
\text { Diario Oficial de la Federación en } \\
\text { cuatro partes los días } 26 \text { de mayo, } 14 \\
\text { de julio, } 3 \text { y } 31 \text { de agosto de 1928.) }\end{array}$ \\
\hline $\begin{array}{l}\text { Cláusulas } \\
\text { finales }\end{array}$ & $\begin{array}{l}\text { Orden de } \\
\text { publicación, Orden } \\
\text { de cumplimiento, } \\
\text { Data, Suscripciones }\end{array}$ & $\begin{array}{l}\text { Rúbrica.- Al C. Lic. Emilio Portes } \\
\text { Gil, Secretario de Estado y del } \\
\text { Despacho de Gobernación.- } \\
\text { Presente. } \\
\text { Lo comunico a usted para su } \\
\text { publicación y demás fines.- Sufragio } \\
\text { Efectivo. No Reelección. } \\
\text { México, a } 30 \text { de agosto de 1928. - El } \\
\text { Secretario de Estado y del Despacho } \\
\text { de Gobernación, Emilio Portes } \\
\text { Gil.-Rúbrica. }\end{array}$ \\
\hline
\end{tabular}

Esta fórmula para la notificación se mantiene hasta nuestros días, lo mismo que el resto de la estructura textual de las leyes de la tradición jurídica codificadora; es decir, organizada según las secciones de las cláusulas iniciales, la parte sustantiva y las cláusulas finales heredadas del documento indiano. Lo demuestran así los decretos promulgatorios del Código Civil vigente, expedido en 1928 (cuadro 8), y de la Ley General de Protección de Datos Personales en Posesión de Sujetos Obligados, publicada en 2017 (cuadro 9), como sucede en prácticamente todos los decretos presidenciales de expedición de leyes del siglo xxI. Obsérvese que el decreto del Código Civil de 1928 cuadro 8) incluye una sección de una breve justificación expositiva, en la que el presidente de la República hace explícita su facultad para expedir leyes. Además, contrario a las máximas de la buscada independencia textual del código en la era de la codificación, este decreto de 1928 se vincula sintácticamente con el código como 
Cuadro 9

DECRETO DE EXPEDICIÓN DE UNA LEY ESPECIAL (2017) Y PARTES TEXTUALES DEL DOCUMENTO INDIANO

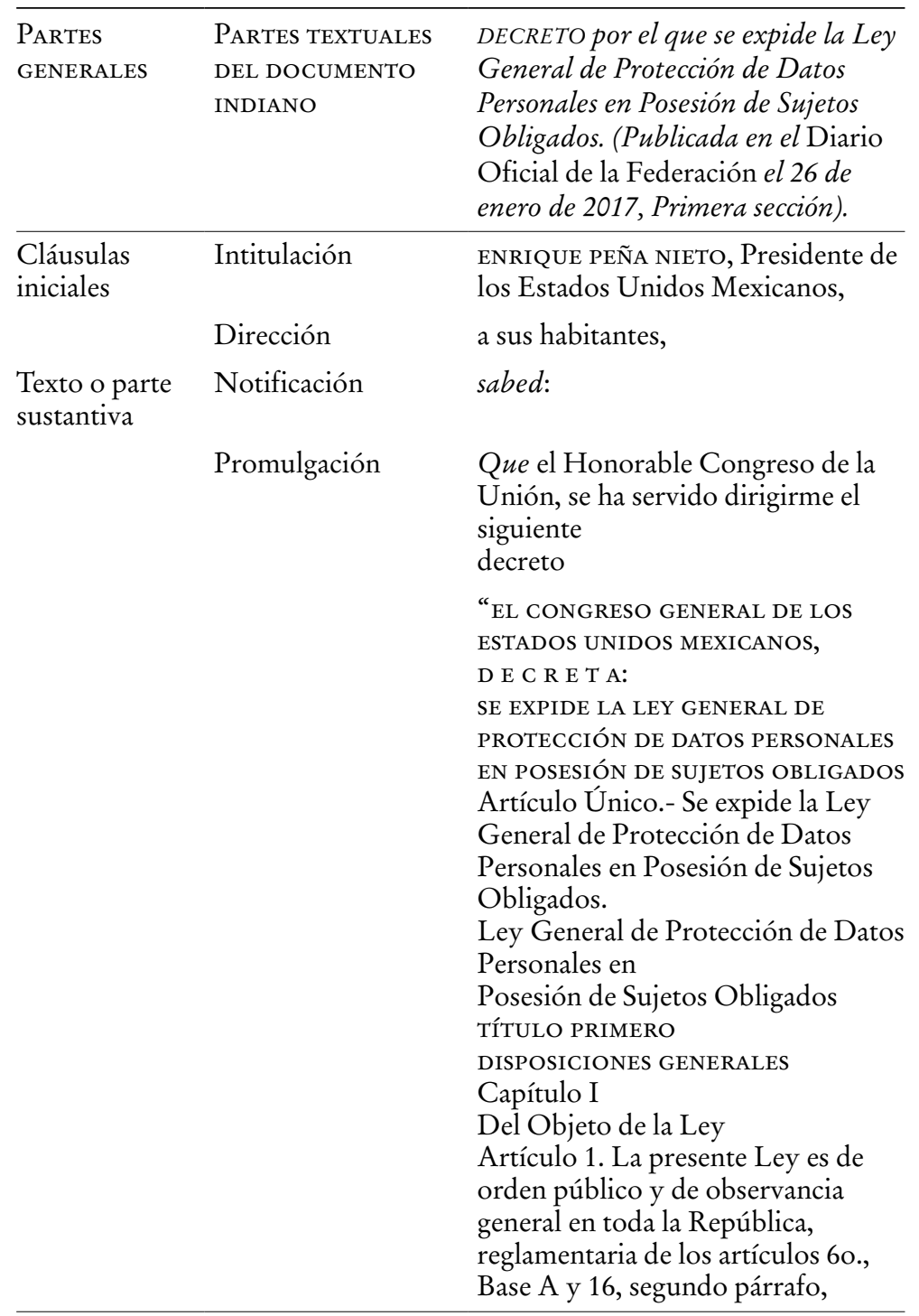


Cuadro 9 (concluye)

\begin{tabular}{|c|c|c|}
\hline $\begin{array}{l}\text { PARTES } \\
\text { GENERALES }\end{array}$ & $\begin{array}{l}\text { PARTES TEXTUALES } \\
\text { DEL DOCUMENTO } \\
\text { INDIANO }\end{array}$ & $\begin{array}{l}\text { DECRETO por el que se expide la Ley } \\
\text { General de Protección de Datos } \\
\text { Personales en Posesión de Sujetos } \\
\text { Obligados. (Publicada en el Diario } \\
\text { Oficial de la Federación el } 26 \text { de } \\
\text { enero de } 2017, \text { Primera sección). }\end{array}$ \\
\hline & Decisión & $\begin{array}{l}\text { de la Constitución Política de los } \\
\text { Estados Unidos Mexicanos, en } \\
\text { materia de protección de datos } \\
\text { personales en posesión de sujetos } \\
\text { obligados. } \\
{[\ldots]}\end{array}$ \\
\hline $\begin{array}{l}\text { Cláusulas } \\
\text { finales }\end{array}$ & $\begin{array}{l}\text { Orden de } \\
\text { publicación, Orden } \\
\text { de cumplimiento, } \\
\text { Data, Suscripciones }\end{array}$ & $\begin{array}{l}\text { Ciudad de México, a } 13 \text { de } \\
\text { diciembre de 2016.- Sen. Pablo } \\
\text { Escudero Morales, Presidente.- Dip. } \\
\text { Edmundo Javier Bolaños Aguilar, } \\
\text { Presidente.- Sen. Lorena Cuellar } \\
\text { [sic] Cisneros, Secretaria.- Dip. } \\
\text { María Eugenia Ocampo Bedolla, } \\
\text { Secretaria.- Rúbricas. } \\
\text { En cumplimiento de lo dispuesto } \\
\text { por la fracción I del Artículo } 89 \\
\text { de la Constitución Política de } \\
\text { los Estados Unidos Mexicanos, } \\
\text { y para su debida publicación y } \\
\text { observancia, expido el presente } \\
\text { Decreto en la Residencia del Poder } \\
\text { Ejecutivo Federal, en la Ciudad de } \\
\text { México, a veinticuatro de enero de } \\
\text { dos mil diecisiete.- Enrique Peña } \\
\text { Nieto.- Rúbrica.- El Secretario de } \\
\text { Gobernación, Miguel Ángel Osorio } \\
\text { Chong.- Rúbrica. }\end{array}$ \\
\hline
\end{tabular}


tal, pues hace de todo el Código Civil el complemento directo del predicado central de la decisión expido, con la frase nominal el siguiente Código civil federal, lo cual destaco en cursivas en la sección de la decisión.

Por su parte, la disposición de 2017 (cuadro 9) no es un código, sino una ley federal que no se desprende de un código en particular, sino directamente de la Constitución federal. De acuerdo con Natalino Irti esto es un síntoma de lo que él ha llamado "la era de la descodificación", pues rompe con la organización piramidal del sistema normativo; el mundo monocéntrico de los códigos se transforma en un sistema jurídico centrífugo y policéntrico y los códigos pasan a ser meras leyes residuales. ${ }^{49}$ Entre otras cosas, de acuerdo con Irti, hay transformaciones lingüísticas en la expresión de las leyes cuyos efectos, según sus palabras, son los siguientes:

Irrumpen así en el lenguaje legislativo, por un lado, indicaciones de programas y de resultados deseables para el bien común y la utilidad social; y, por el otro, terminologías científicas, económicas, industriales, conexas con los problemas de la edad contemporánea. Las leyes se multiplican no tan sólo en el número, sino en las modalidades expresivas y sintácticas, cada una adaptándose al léxico particular o a la simple jerga de la materia regulada. [...] La variedad expresiva, que era propia de los negocios privados, se transfiere a las leyes, desprovistas por la novedad de los campos de regulación, de toda conexión con las fuentes romanísticas y con el vocabulario riguroso de la doctrina..$^{50}$

Es decir, según Irti las también llamadas leyes especiales se formulan casi como contratos o negocios privados programáticos que buscan satisfacer intereses de gremios o grupos

${ }^{49}$ IRTi, La edad de la descodificación.

50 IRTI, La edad de la descodificación, p. 26. 
particulares de la sociedad, de tal manera que pierden la generalidad y la abstracción idealizada del estilo codificador; las fuentes románicas tradicionales ceden su lugar a universos referenciales muy acotados y especializados; de ahí que este tipo de leyes acudan a definiciones y terminologías de ámbitos no jurídicos. Desde el punto de vista histórico, Irti mira esta técnica legislativa como "radicalmente modificada". ${ }^{51}$ Ante esta nueva realidad, cacaso podríamos pensar que la era de la descodificación inaugura una nueva tradición textual, que se distinguiría de las tradiciones codificadora moderna y de la medieval renacentista?

En términos de la estructura textual, la respuesta es "no". Por un lado, las leyes especiales siguen muy rigurosamente la organización de las normas en títulos, capítulos, artículos, fracciones e incisos de la tradición codificadora. Por otro lado, los decretos para la expedición de dichas leyes, además de seguir los procesos jurídicos constitucionales de los Estados modernos, se configuran según los cánones de los documentos diplomáticos de la tradición medieval y renacentista.

Se demuestra todo esto en el decreto con el que se expide la Ley General de Protección de Datos Personales en Posesión de Sujetos Obligados (cuadro 9), publicada en enero de 2017. Obsérvese, como en los diplomas reales del siglo XI, que el predicado de la notificación sabed subordina la oración que introduce el decreto del Congreso que expide la ley. Destaco en cursivas este vínculo sintáctico entre la notificación y la promulgación.

\section{TRADICIONES CULTURALES, ESTRATOS HISTÓRICOS Y HERMENÉUTICA}

En el ejercicio comparativo de las tradiciones textuales en los documentos que expiden disposiciones jurídicas desde la Edad Media hasta nuestros días, con particular atención a las

51 IRTI, La edad de la descodificación, p. 26. 
tradiciones jurídicas y textuales pertinentes en la Nueva España y México, hemos podido comprobar que las innovaciones en el ámbito jurídico no conllevan ni paralela ni simultáneamente innovaciones en el ámbito textual. En otras palabras, que aunque las tradiciones jurídicas y las discursivas son fenómenos culturales, esto no implica que sus ritmos de desarrollo históricos sean sincrónicos. De hecho, hemos observado que las tradiciones textuales de tipo escritural y formulaico son más conservadoras que las tradiciones de las ideas jurídicas románicas, a pesar de ser éstas también más conservadoras que otras tradiciones culturales. ${ }^{52}$

Esto tiene sentido si se toma en cuenta uno de los principios de la teoría de las tradiciones discursivas: los emisores que configuran nuevos significados, para lograr sus fines comunicativos, se sirven de los moldes discursivos existentes, que son repetitivos y conocidos por la comunidad de destinatarios, pues las nuevas tradiciones, como ha señalado Peter Koch, no surgen ex nibilo. ${ }^{53}$

Más aún, la combinación de los elementos textuales repetidos por generaciones con los elementos innovadores no es exclusiva de las tradiciones discursivas; es propio de cualquier tradición cultural. En el mundo jurídico, por ejemplo, esto se revela también en las reflexiones de Paolo Grossi acerca de la era de la codificación. A pesar de que Grossi critica a aquellos que han tratado de ver más continuidad que ruptura en los códigos del Estado moderno respecto del derecho romano clásico, apunta también en esta profunda transformación jurídica el fenómeno de la convivencia entre tradición y cambio. Al referirse al Código Napoleón, escribe:

Resulta obvio que, en el ámbito de los contenidos, el pasado puede hacer sentir su voz en el interior del Código en alguna regla

${ }^{52}$ Cuestión también desarrollada en Vázquez Laslop, "Los ritmos de las tradiciones jurídicas".

${ }^{53} \mathrm{KocH}$, "Diskurstraditionen", p. 60. 
o en algún principio particular. Y no sólo porque a Bonaparte le conviene exhumar algunos cadáveres que la Revolución había ya sepultado [...], sino por la elemental razón de que el Código no es una nube que sobrevuela sin tocar el paisaje histórico, sino más bien un ordenamiento nuevo de este paisaje concreto; paisaje que, en nuestra opinión, es modelado y renovado en su diseño general, en sus principios fundamentales, en sus fuentes y, en definitiva, en su estructura, pero que no nace de la nada. ${ }^{54}$

La combinación de la repetición y la innovación es, entonces -por decirlo de alguna manera-, una propiedad de la historicidad. Reinhart Koselleck ya había interpretado que existía una analogía entre la evolución de la historia social y la evolución de la historia conceptual. Desde su punto de vista, la historicidad de los hechos singulares sólo se percibe si tomamos en cuenta que éstos se producen en condiciones que se han reproducido regularmente a lo largo del tiempo y que, por ello, son ya presupuestas. ${ }^{55}$ Así, tales condiciones se configuran como patrones que se repiten por generaciones en los ámbitos culturales y terminan estableciéndose como verdades religiosas, metafísicas, mágicas, científicas, etc., que sirven de fundamentos en las relaciones humanas. ${ }^{56}$ Sin embargo, a pesar de su arraigo y de la apariencia de su estabilidad -nos dice Koselleck-, estas estructuras de larga duración también están sufriendo modificaciones por el dinamismo propio de los aconteceres sociales y las experiencias e historias individuales, sólo que sus ritmos de cambio son mucho más lentos. ${ }^{57}$

\footnotetext{
54 Grossi, De la codificación, p. 81.

55 Koselleck, L'expérience de l'bistoire, p. 117.

56 Koselleck, Los estratos del tiempo, p. 41. Verdades incontrovertibles y, a veces, hasta prerreflexivas o inconscientes, diría Jürgen Habermas con Husserl, a propósito del saber de fondo, el más profundo del mundo de la vida. HaberMAs, Pensamiento postmetafísico, p. 95.

57 Koselleck, Los estratos del tiempo, p. 81.
} 
Aunque cada ámbito cultural tiene sus propias lógicas ${ }^{58} \mathrm{y}$ ritmos -lo cual obliga a las investigaciones empíricas a establecer límites temáticos-, el estudio del entramado entre la historia conceptual y la historia social demanda un procedimiento interdisciplinario. ${ }^{59} \mathrm{Al}$ respecto, sabemos que los aspectos lingüísticos en la teoría de la historia conceptual de Koselleck se centran, particularmente, en la relación entre los conceptos y el léxico, siempre vinculada a los ámbitos históricos correspondientes. ${ }^{60} \mathrm{Al}$ análisis léxico podríamos añadir otros niveles lingüísticos, como el textual que aquí he ejemplificado. En efecto, la complejidad de los moldes que configuran la actividad verbal como parte nuclear de los hechos históricos puede analizarse según los niveles de los saberes lingüísticos delineados por Coseriu (v. \S, "Saberes lingüísticos" supra), una tarea todavía pendiente de desarrollo. ${ }^{61}$

En cuanto a la temporalidad histórica, Koselleck ha demostrado que ésta no puede concebirse de manera homogénea, sino que es relativa según las temporalidades propias de los distintos niveles de la realidad social. Para ello propone su conocida teoría de los estratos del tiempo, cuya ventaja es "poder medir distintas velocidades, aceleraciones o demoras, y hacer así visibles distintos modos de cambio que ponen de manifiesto una gran complejidad temporal". ${ }^{62}$ En otra parte afirma:

${ }^{58} \mathrm{Si}$ entendemos, con Ernst Cassirer, que la interpretación -en este casohistórica de las tradiciones e innovaciones jurídicas y textuales ha de tomar en cuenta también el "sentido" o la lógica de cada forma cultural y sus funciones para, a partir de ello, entender y explicar la relación que guardan entre sí. CASSIRER, Las ciencias de la cultura, pp. 158-160.

59 Koselleck, L'expérience de l'bistoire, p. 104.

${ }^{60}$ Con sus colaboradores Otto Brunner y Werner Conze, trabaja la edición en ocho tomos de Geschichtliche Grundbegriffe (Historisches Lexikon zur politisch-sozialen Sprache in Deutschland), 1972-1997.

${ }^{61}$ Véase Vázquez Laslop, "Los ritmos de las tradiciones jurídicas".

${ }^{62}$ Koselleck, Los estratos del tiempo, p. 38. 
Même si les actes langagiers et les actes effectifs restent entrelacés dans la synchronie - qui est elle-même une abstraction -, l'évolution diachronique - qui reste elle-même une construction théorique-ne suit pas les mêmes rythmes ni la même chronologie dans l'histoire « réele » que dans l'histoire des concepts. Il arrive que la réalité ait changé bien avant que son évolution ne soit conceptualisée, et il arrive que des concepts aient été formés qui ont ouvert la voie à de nouvelles réalités. ${ }^{63}$

La manera de entender el devenir histórico, en la visión de Koselleck, no es, por lo tanto, lineal, sino producto de la interpretación de la complejidad de la experiencia y la percepción de la temporalidad humana en diversos estratos (desde el individual y el generacional hasta el que trasciende varias generaciones) y en los modos de conceptualizarlos. A fin de cuentas, la historia, más que una teoría de los aconteceres reales, es una historia conceptual, pues es en la actividad lingüística donde la interpretación de la experiencia histórica cobra significado. No obstante, de nuevo, los ritmos de la actividad lingüística y de los aconteceres sociales a los que aquélla da sentido son asincrónicos.

De todas formas, para cerrar el círculo explicativo, además de identificar los principios de la lógica y los ritmos de cada tradición cultural, es necesario interpretar las relaciones que éstas guardan entre sí. Para ello, el método hermenéutico, que permite delimitar y ampliar los horizontes de observación retrospectiva, con plena consciencia del sentido de la propia experiencia del presente -es decir, del punto de observación-, se nos ofrece como la mejor opción de reconstrucción histórica, ${ }^{64}$ en el entendido de que las tradiciones culturales que buscamos explicar bien pueden ser las de nuestra experiencia presente. Como señala Hans-Georg Gadamer, "[u]n pensamiento verdadera-

63 Koselleck, L'expérience de l'histoire, p. 117.

64 Koselleck, Los estratos del tiempo, p. 79. 
mente histórico tiene que ser capaz de pensar al mismo tiempo su propia historicidad". ${ }^{65}$ Sólo así es posible "ganar el horizonte de la observación hermenéutica":

La elaboración de la situación hermenéutica significa [...] la obtención del horizonte correcto para las cuestiones que se nos plantean de cara a la tradición. [...] Ganar un horizonte quiere decir siempre aprender a ver más allá de lo cercano y de lo muy cercano, no desatenderlo, sino precisamente verlo mejor integrándolo en un todo más grande y en patrones más correctos. ${ }^{66}$

Así, por ejemplo, es necesario asumir una actitud de extrañeza desde una perspectiva textual, por un lado, ante el modelo del decreto para expedir leyes mexicanas y, por otro, desde una perspectiva jurídica, ante la concepción de la ley positiva y sistematizada a modo de código como única fuente del derecho.

La observación de las diversas dimensiones culturales en su complejidad ha de partir, entonces, de la consciencia del observador acerca de su posición histórica, digamos, en el momento presente (subjetivo). Este observador, simbolizado como ' $\alpha$ ' en el esquema $1,{ }^{67}$ en esa posición, está en posibilidad de distinguir, en primer lugar, los objetos culturales cuya historia se propone estudiar; por ejemplo, las leyes mexicanas, los paradigmas jurídicos y los acontecimientos político-sociales, como la independencia de la América septentrional del imperio español, incluyendo los antecedentes del intento de establecimiento de una monarquía constitucional en España, lo que se representa en un corte temporal delimitado con líneas punteadas verticales en el esquema. En otro nivel, en segundo lugar, el observador puede identificar los moldes culturales o simbólicos de dichos

${ }^{65}$ Gadamer, Verdad y método, vol. 1, p. 370.

${ }^{66}$ Gadamer, Verdad y método, vol. 1, pp. 373 y 375.

${ }^{67}$ También reproducido en VázQuez LasLop, "Los ritmos de las tradiciones jurídicas”, p. 165. 
objetos, que, de hecho, se han configurado según tradiciones que trascienden la propia delimitación temporal. Digamos, en la dimensión de los acontecimientos político-sociales, la propia independencia con los antecedentes respectivos en España y en la Nueva España y sus motivaciones ideológicas; respecto de las tradiciones jurídicas en dicho corte temporal, la tradición del derecho indiano y la entrada de la tradición codificadora y, por último, en cuanto a las tradiciones textuales, la coincidencia en ese momento histórico de los cánones de la retórica de tipo escolástico y de la expresión de las leyes en artículos, capítulos y títulos presentes en los textos legislativos, así como en los textos administrativos de carácter público. En un tercer nivel es indispensable que el observador reconozca las tradiciones culturales en las que está inmerso, las cuales pueden ser parte de su objeto de estudio; por ejemplo, el reconocer que desde el punto de vista político-social el observador se mueve en un mundo republicano y democrático, que las leyes se formulan todavía según el paradigma codificador y que los moldes textuales, digamos, de los decretos siguen combinando estructuras provenientes del ars dictaminis y de las leyes articuladas. El cuarto nivel se corresponde con el establecimiento de relaciones entre los objetos culturales en observación. Gracias a todo esto, en un último nivel, el observador puede contar con elementos para delimitar los entornos comunicativos que enmarcan la generación de cada disposición legislativa o de sus tipos (por ejemplo, decretos expedidos en el primer imperio mexicano, los decretos expedidos por el primer Congreso mexicano como parte de una república federal, todo lo cual puede compararse, después, con los decretos expedidos en un periodo de transición democrática en el cambio del siglo xx al xxI).

Cuando hablo de los entornos comunicativos me refiero, de nuevo, a la teoría lingüística de Eugenio Coseriu. Como parte de su lingüística integral, Coseriu destaca que hablar es "decir algo nuevo", que se inserta comúnmente en la tradición; pero 
lo que se dice es menos de lo que se expresa y se entiende. ${ }^{68}$ En efecto, además de que los patrones de la tradición evocan lo no expresado (v. \"Saberes lingüísticos”, supra), las circunstancias del hablar son el fondo de lo dicho. Éstas son los entornos que, en palabras de Coseriu, "orientan todo discurso y le dan sentido, y hasta pueden determinar el nivel de verdad de los enunciados". ${ }^{69}$ Mi propuesta aquí es que los niveles culturales a los que me he referido bien pueden combinarse con algunos de los entornos coserianos. Coseriu distingue varios tipos de entornos, pero tomo, por ahora, sólo la región para ejemplificar el esbozo de esta idea. La región es, según la definición de Coseriu, "el espacio dentro de cuyos límites un signo funciona en determinados sistemas de significación. Tal espacio está delimitado, en un sentido, por la tradición lingüística y, en otro sentido, por la experiencia acerca de las realidades significadas". ${ }^{70}$ De tal manera que la región abarca no sólo los objetos textuales (y todo lo que implican lingüísticamente), sino las experiencias jurídicas y político-sociales que le dan sentido a cada texto. Por ello, el área delimitada con las líneas punteadas verticales en el esquema corresponde a estos tres espacios culturales.

Entre otras cosas, Coseriu agrega acerca de la región su relevancia semántica en términos de la relación entre el lenguaje y la realidad extralingüística: "Muchos matices semánticos de las palabras dependen, en gran parte, de las diferencias de 'región'. Una palabra empleada fuera de su 'ámbito' puede significar la misma realidad objetiva, pero ya no significa del mismo modo, pues su 'evocación' es distinta". ${ }^{71}$

Me parece que esta idea es compatible con la visión histórica de los conceptos de Reinhart Koselleck, particularmente, si tomamos como región (en el sentido coseriano) un complejo

\footnotetext{
68 Coseriu, “Determinación y entorno”, p. 45.

69 Coseriu, "Determinación y entorno”, p. 45.

70 Coseriu, "Determinación y entorno”, p. 47.

71 Coseriu, "Determinación y entorno”, p. 47.
} 


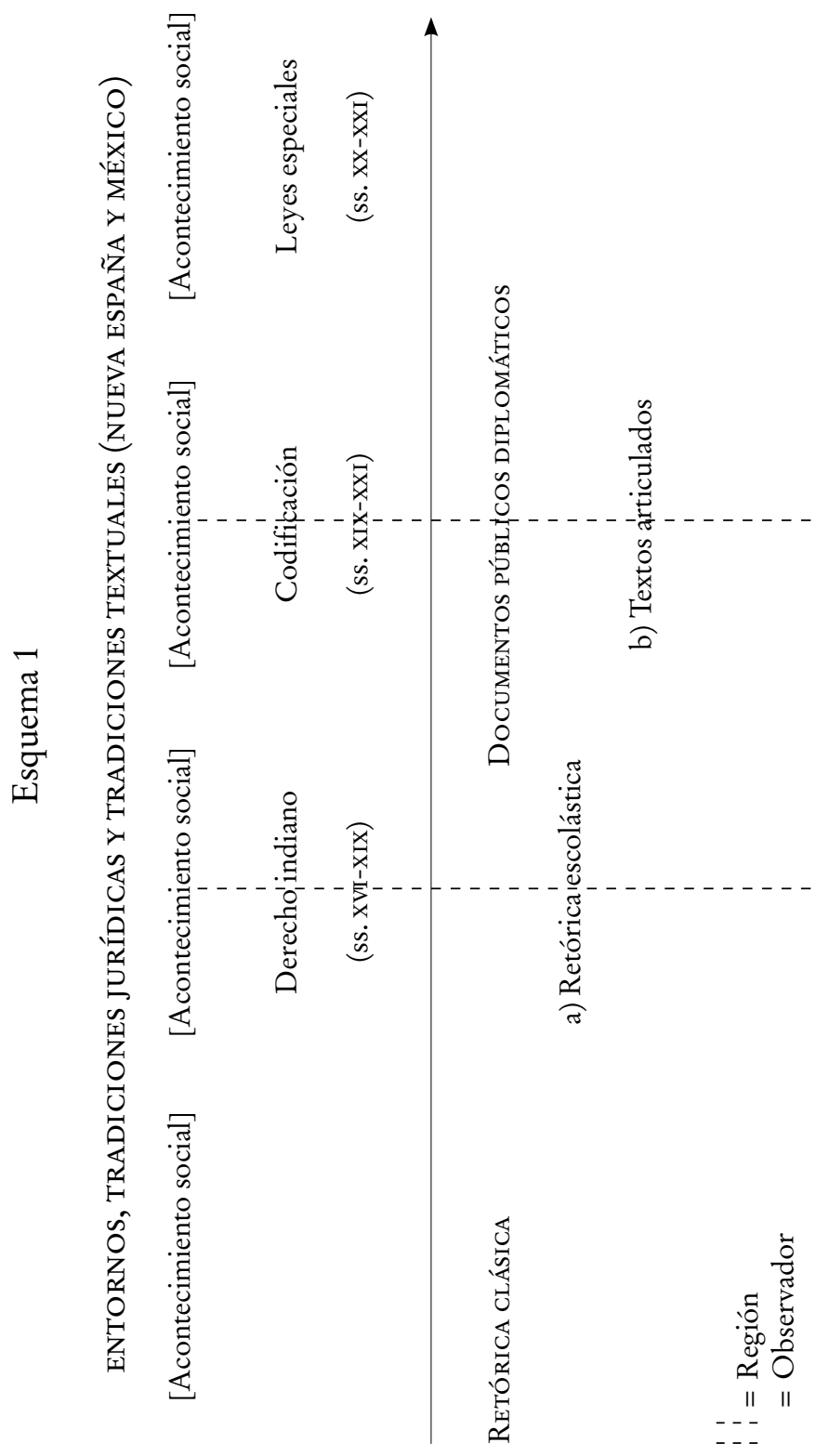


de objetos culturales que resultan en una bisagra aceleradora de cambios sociales y políticos, asociados a nuevos modos de evocación lingüística, una idea que valdría la pena explorar.

\section{CONCLUSIÓN}

En el quehacer histórico es necesario tomar consciencia de la propia historicidad de las fuentes textuales, la cual sólo puede entenderse por su naturaleza cultural. Ello implica que su estudio no puede limitarse a la perspectiva de una sola disciplina social o humanística. Esto es bien conocido ya en la filología. No obstante, el desarrollo que han alcanzado las ciencias sociales y las humanidades en las primeras décadas del siglo XxI hace posible ampliar la perspectiva de su estudio con las nuevas metodologías que aportan disciplinas como la lingüística, la historia, la diplomática y otras tantas según el o los ámbitos culturales a los que pertenecen dichas fuentes textuales, como el jurídico que se ha tratado en este artículo. Se ha demostrado que, a pesar de los fuertes vínculos entre dichos ámbitos culturales, cada esfera del saber humano cuenta con tradiciones y moldes específicos cuyo dinamismo histórico tiene sus propios ritmos y sus reglas particulares. Se ha propuesto que una interpretación histórica de las relaciones entre los diversos objetos culturales, por un lado, ha de tomar en cuenta la complejidad y relatividad del tiempo histórico y, por otro, ha de permitir al observador hacer consciencia de su propia historicidad, es decir, de que él mismo se desenvuelve en el entramado de las tradiciones culturales que busca interpretar. La hermenéutica cumple el objetivo de enlazar de manera coherente y sistemática la diversidad de las perspectivas culturales y, dentro de esta perspectiva, se abre la posibilidad de vincular elementos de la lingüística integral de Eugenio Coseriu con teorías de otras disciplinas humanísticas, como la historia conceptual de Reinhart Koselleck. 


\section{REFERENCIAS}

Arenal Fenochio, Jaime del, Historia mínima del derecho en Occidente, México, El Colegio de México, 2016.

Brunner, Otto, Werner Conze y Reinhart Koselleck (eds.), Geschichtliche Grundbegriffe (Historisches Lexikon zur politisch-sozialen Sprache in Deutschland), Stuttgart, Klett-Cotta, 1972-1997, 8 tomos.

Cassirer, Ernst, Las ciencias de la cultura, traducción de Wenceslao Roces, México, Fondo de Cultura Económica, 2014.

Coseriu, Eugenio, “Determinación y entorno. Dos problemas de una lingüística del hablar", en Romanistisches Jabrbuch, 7 (1955), pp. 29-54.

Coseriu, Eugenio, Sincronia, diacronia e historia. El problema del cambio lingüístico, Madrid, Gredos, 1973.

Coseriu, Eugenio, Lecciones de lingüística general, Madrid, Gredos, 1981.

Coseriu, Eugenio, Lingüística del texto. Introducción a la bermenéutica del sentido, Madrid, Arco/Libros, 2007.

Dublán, Manuel y José María Lozano, Legislación mexicana ó Colección completa de las disposiciones legislativas expedidas desde la independencia de la república 1687-1910, México, Imprenta del Comercio, a cargo de Dublán y Lozano hijos, 1876-1904.

Dublán, Manuel y José María Lozano, Legislación mexicana ó colección completa de las disposiciones legislativas expedidas desde la independencia de la república, t. XI, México, Imprenta del Comercio, de Dublán y Chávez, á cargo de M. Lara (hijo), 1879.

Encinas, Diego de, Cedulario indiano, recopilado por ..., Oficial mayor de la Escribanía de Cámara del Consejo Supremo y Real de las Indias. Alfonso García Gallo (estudio e índices). Reproducción facsímil de la edición única de 1596, Libro tercero, Madrid, Ediciones Cultura Hispánica, 1945.

Frank, Barbara, Thomas HaYe y Doris Tophinke (eds.), Gattungen mittelalterlicher Schriftlichkeit, Tubinga, Narr, 1997.

GadAmer, Hans-Georg, Verdad y método, traducción de Ana Agud Aparicio y Rafael de Agapito, Salamanca, Ediciones Sígueme, vol. 1, 2012. 
García Gallo, Alfonso, "La ley como fuente del derecho en Indias en el siglo XvI", en Estudios de historia del Derecho indiano, III Congreso del Instituto Internacional de Historia del Derecho Indiano, Madrid, Instituto Nacional de Estudios Jurídicos, 1972, pp. 169-285.

Glessgen, Martin, Johannes Kabatek y Harold Völker (eds.), Repenser la variation linguistique, Actes du Colloque DIA II à Zrich (12-14 sep. 2016), Strasbourg, Eliphi, 2018.

GonzÁlez, María del Refugio, El derecho civil en México 1821-1871 (Apuntes para su estudio), México, Universidad Nacional Autónoma de México, 1988.

Grossi, Paolo, De la codificación a la globalización del derecho, traducción y notas de Rafael D. García Pérez, Pamplona, Thomson Reuters y Aranzadi, 2010.

Grossi, Paolo, El novecientos jurídico: un siglo posmoderno, traducción de Clara Álvarez, Madrid, Marcial Pons, 2011.

Guzmán Brito, Alejandro, “'Codex”, en Revista de Estudios HistóricoJurídicos, 9 (1984), pp. 107-144.

Habermas, Jürgen, Pensamiento postmetafísico, traducción de Manuel Jiménez Redondo, México, Taurus, 1998.

Hummel, Martin, Bettina Kluge y María Eugenia Vázquez Laslop (eds.), Formas y fórmulas de tratamiento en el mundo hispánico, México, El Colegio de México, 2010.

IRTI, Natalino, La edad de la descodificación, traducción e introducción de Luis Rojo Ajuria, Barcelona, Bosch, 1992.

KaвateK, Johannes, “Eugenio Coseriu (1921-2002)”, en Revista Internacional de Lingüistica Iberoamericana 1: 2 (2003), pp. 179-181.

Kabatek, Johannes, Die Bolognesische Renaissance und der Ausbau romanischer Sprachen. Juristische Diskurstraditionen und Sprachentwicklung in Südfrankreich und Spanien im 12. und 13. Jahrbundert, Tubingan, Niemeyer, 2005.

Kabatek, Johannes, “Tradiciones discursivas y cambio lingüístico”, en Lexis, 29: 2 (2005), pp. 151-177. 
KABATEK, Johannes, "Las tradiciones discursivas entre conservación e innovación", en Rivista di Filologia e Letterature Ispaniche, 10 (2007), pp. 331-348.

Косн, Peter, "Diskurstraditionen: zu ihrem sprachtheoretischen Status und ihrer Dynamik", en Frank, Haye y Tophinke (eds.), 1997, pp. 43-79.

Kосн, Peter, "Urkunde, Brief und öffentliche Rede. Eine diskurstraditionelle Filiation im 'Medienwechsel'”, en Das Mittelalter. Perspektiven mediävistischer Forschung, 3: 1 (1998), pp. 13-44.

Koselleck, Reinhart, L'expérience de l'bistoire, traducción de Diane Meur, París, Seuil y Gallimard, 1997.

Koselleck, Reinhart, Los estratos del tiempo: estudios sobre la historia, traducción de Daniel Innerarity, Barcelona, Paidós y Universidad Autónoma de Barcelona, 2001.

Loureda Lamas, Óscar y Reinhard Meisterfeld, "Eugenio Coseriu y su legado científico”, en Estudis Romànics, 29 (2007), pp. 269-277.

Montesquieu (Charles Louis de Secondat de), De l'esprit des lois (Introduction, chronologie, bibliographie, relevé de variantes et notes par Robert Derathé), París, Garnier, 1973.

Murphy, James J., Rhetoric in the Middle Ages. A History of Rhetorical Theory from St. Augustine to the Renaissance, Berkeley, Los Ángeles y Londres, University of California Press, 1974.

Oesterreicher, Wulf, “Zur Fundierung von Diskurstraditionen”, en Frank, Haye y Tophinke (eds.), 1997, pp. 19-41.

Real Díaz, José Joaquín, Estudio diplomático del documento indiano, Sevilla, Escuela de Estudios Hispanoamericanos del Consejo Superior de Investigación Científica, 1970.

Schlieben-Lange, Brigitte, Traditionen des Sprechens. Elemente einer pragmatischen Sprachgeschichtsschreibung, Stuttgart, Kohlhammer, 1983.

TAmaYo, Alberto, Archivística, diplomática y sigilografía, Madrid, Cátedra, 1996.

Tau Anzoátegui, Víctor, “Acerca de la elaboración y publicación de la ley en el Derecho Indiano", en Anuario de Historia del Derecho Español, LXxx (2010), pp. 157-181. 
Tena Ramírez, Felipe, Derecho constitucional mexicano, México, Porrúa, 2000.

Tomás y Valiente, Francisco, Manual de historia del derecho español, Madrid, Tecnos, 1981.

VÁzquez Laslop, María Eugenia, "Tradiciones jurídicas y tradiciones textuales de las leyes mexicanas (siglos xvi al xxi)", en Cuadernos de la ALFAL, 6, (2014), pp. 87-104 <http://www.mundoalfal.org/indexe.htm>.

VÁzquez Laslop, María Eugenia, “Tradiciones e innovaciones jurídicas y textuales: codificación y descodificación en las leyes mexicanas de los siglos xix al xxi”, en Zimmermann (ed.), 2014, pp. 167-204.

VÁzquez Laslop, María Eugenia, "Cohesión sintáctica y argumentación en las leyes mexicanas del siglo XIX”, en José María Enguita (dir.), Actas del X Congreso Internacional de Historia de la Lengua Española (Zaragoza, 7-11 de septiembre de 2015) [en prensa].

VázQuez Laslop, María Eugenia, "Los ritmos de las tradiciones jurídicas y textuales: historicidad, entornos y hermenéutica”, en Glessgen, KabAteK y VÖLKER (eds.), 2018, pp. 155-168.

VÁzquez Laslop, María Eugenia y Leonor Orozco, "Formas de tratamiento del español en México”, en Hummel, Kluge y Vázquez Laslop (eds.), 2010, pp. 247-270.

Zimmerman, Klaus (ed.), Prácticas y políticas lingüísticas: nuevas variedades, normas, actitudes y perspectivas, Madrid, Iberoamericana, Editorial Vervuert, 2014. 